

\section{Public \\ JOURNAL OF \\ Transportation}

Gary L. Brosch, Editor

Patricia Henderson, Managing Editor

Editorial Board

Robert B. Cervero, Ph.D.

University of California, Berkeley

Chester E. Colby

Metro-DadeTransitAgency

Gordon Fielding, Ph.D.

University of California, Irvine

David J. Forkenbrock, Ph.D.

University of lowa

JoséA. Gómez-lbáñez, Ph.D.

Harvard University
Naomi W. Ledé, Ph.D.

Texas Southern University

William W. Millar American Public TransitAssociation

Sandra Rosenbloom, Ph.D.

University of Arizona

Lawrence Schulman

Orbital Sciences Corp.

George Smerk, D.B.A.

Indiana University

\section{$\|_{\text {CUTR }}$}

The Journal of Public Transportation (ISSN 1077-291X) is published quarterly by the Center for Urban Transportation Research (CUTR) in the College of Engineering at the University of South Florida. The contents of this document reflect the views of the authors, who are responsible for the facts and the accuracy of the information presented herein. This document is disseminated under the sponsorship of the U.S. Department of Transportation, University Research Institute Program, in the interest of information exchange. The U.S. Government assumes no liability for the contents or use thereof. Subscriptions are complimentary and may be obtained by contacting the Center for Urban Transportation Research, University of South Florida, 4202 E. Fowler Avenue, CUT 100, Tampa, FL 33620-5375, (813) 974-3120, email:phenders@cutr.eng.usf.edu. 


\section{Public solvestor Transportation}

Volume 1, No. 4, 1997

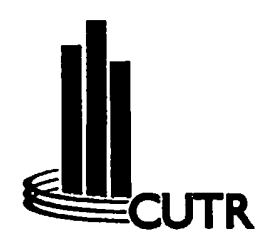

C 1997 Center for Urban Transportation Research

National Urban Transit Institute

Center for Urban Transportation Research

College of Engineering - University of South Florida

4202 E. Fowler Avenue, CUT 100, Tampa, FL 33620-5375

(813) $974-3120 \cdot \operatorname{Fax}(813) 974-5168$

E-mail:phenders@cutr.eng.usf.edu

Web Site: http://www.cutr.eng.usf.edu 


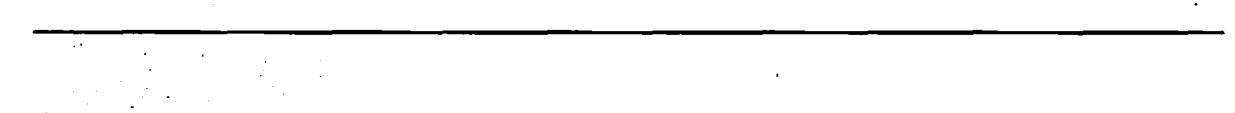
$\therefore \quad:$ 


\section{Public Journalor \\ Transportation}

Volume 1, No. 4, 1997

\section{Contents}

Developing Customer-Based Measures of Overall Transportation Service

Quality in Colorado: Quantitative and Qualitative Approaches

Lawrence F. Cunningham, Clifford Young \& Moonkyu Lee

Transit Subsidies in New York and Chicago: Local, State and Federal Assistance in a Historical Context

Eric Petersen

Evaluation of AVL Technologies for Paratransit in

Small and Medium-Sized Urban Areas

Gary S. Spring, John Collura \& Kenneth B. Black

Design and Development of a Bus Stop Inventory to

Support an Intelligent Transportation System:

The MARTA Experience

Wayne Sarasua, Robert Awuah-Baffour,

Mark Fawley, Carton Byers \& Jeffery Orton

Market, Politics, and Environmental Policy Issues for Public Transit

DavidA. Hensher \& Michael E. Beesley

"Our troubled planet can no longer afford the luxury of pursuits confined to an ivory tower. Scholarship has to prove its worth, not on its own terms, but by service to the nation and the world. "

- Oscar Handlin 



\title{
Developing Customer-Based Measures of Overall Transportation Service Quality in Colorado: Quantitative and Qualitative Approaches
}

\author{
Lawrence F. Cunningham \\ Clifford E. Young \\ University of Colorado at Denver \\ Moonkyu Lee \\ Yonsei University
}

\section{Abstract}

Measurement of customers' perceptions of service quality is crucial to successful service management. This article focuses on the measurement of service quality in Colorado's transportation system, including all transportation modes, transportation infrastructure issues, and special emphasis on public transportation in metropolitan areas. It discusses quantitative and qualitative approaches to transportation service quality measurement. The study also contrasts the results of quantitative and qualitative measurements and methodologies for assessing transportation service quality. Finally, the paper offers recommendations for the use of these methodologies by transportation planners, especially those operating in the public transportation sphere. 


\section{Introduction}

Valid, accurate measurement of customers' quality perceptions (Smerk 1992) are important to successful implementation of the Intermodal Surface Transportation Efficiency Act (ISTEA). Service quality, in particular, has attracted attention and inspired academic research, resulting in generic measures of overall service quality (e.g., Bitner, Booms, and Tetreault 1990; Parasuraman, Zeithaml, and Berry 1988) and unique measures designed for specific industries (e.g., Pullen 1993 and Stank 1993). While some research has been conducted specific to airlines and logistics (e.g., Cunningham and Lee 1996; Young, Cunningham and Lee 1994a, 1994b, 1992; Hopkins, Strasser, Hopkins, and Foster 1993; Lee et al. 1993; Gourdin and Kloppenborg 1991), little research has been conducted on service quality transportation issues by public transportation planning agencies (Cunningham, Young, and Kroeter 1995, 1994).

This study represents complementary approaches to measuring transportation service quality in Colorado (Dunn, Seaker, and Waller 1994; Seaker, Waller, and Dunn 1993), which included a quantitative telephone survey; a qualitative, critical incident technique (CIT); and a focus group approach. The methodologies complemented each other (Campbell and Fiske 1959; Jick 1979). Research followed a hierarchical process. Specific measures were initially developed based on quantitative telephone survey pretests (Study 1), followed by CIT and focus group research (Study 2). The article explains the research procedure in detail. It also reports and compares findings from the two studies and discusses their implications for transportation planners.

\section{Service Quality: Quantitative and Qualitative Approaches To Its Measurement}

\section{Quantitative Approach}

Perceived service quality, viewed as a type of attitude or a long-run overall evaluation (Bitner 1990; Bolton and Drew 1991; Parasuraman et al. 1988), is formed on the basis of piecemeal evaluation of individual service attributes and features that are integrated to form an overall judgment. This assumption is the 
basis for multi-attribute measures of service quality, such as the SERVQUAL model (Parasuraman et al. 1985, 1988, 1991), which utilizes 22 attitude scales to measure perceived quality of tangibles, reliability, responsiveness, assurance, and empathy.

Although SERVQUAL has gained popularity in measuring service quality in a wide spectrum of industries (e.g., Crompton and Mackay 1989; Fick and Ritchie 1991; Johnson, Dotson, and Dunlap 1988; Woodside, Frey, and Daly 1989; Young, Cunningham, and Lee 1994), it has limitations. SERVQUAL measures are essentially generic rather than industry-specific, and the model is built upon an assumption of multi-attribute evaluations; thus, it does not capture categorical product or a service judgments made on the basis of product cues or service incidents (Fiske and Pavelchak 1986; Sujan 1985).

\section{Qualitative Approach}

The best known qualitative method for assessing service quality is the critical incident technique (CIT) developed and refined by Bitner (Bitner et al. 1990; Bitner, Nyquist, and Booms 1985), which states that service providers should focus on "critical incidents" that make customers happy or unhappy.

Major weaknesses of qualitative technique are that the data are hard to analyze; are susceptible to subjective interpretations due to the unstructured, nonstandardized nature of the technique; and are difficult to compare and obtain objective results (Weiss 1968).

Thus, for more valid and reliable data, both qualitative and quantitative measures were used (Campbell and Fiske 1959; Dunn, Seaker, and Waller 1994; Jick 1979; Seaker, Waller, and Dunn 1993) in these two studies of the overall transportation system, including private transportation, the transportation infrastructure, the public and private intercity transportation systems, and public transportation systems in metropolitan areas. In Study 1, service-specific measures were used in a survey setting, and in Study 2, data were collected through critical incident and focus group techniques. Each study is described and then results are compared. 


\section{Study 1: Survey Research}

New measures were customized for this study. Transportation services issues in Colorado were identified via (1) literature search of current concepts and theories, (2) examination of other state Department of Transportation (DOT) activities, and (3) focus groups and personal interviews with public, metropolitan, and regional transportation officials and officials at the state level. These components led to the development of a questionnaire administered to individual households throughout the state.

\section{Questionnaire Development}

A preliminary questionnaire reflecting contemporary transportation issues was developed from a literature search of databases and publications. Other state DOTs were contacted about techniques for measuring public perceptions, and two 2-hour focus groups (14 participants each) and 14 personal interviews were conducted to solicit insights. Extensive efforts were maintained to ensure diversity in the individuals selected for this process.

After a series of pretests, preliminary results were presented to the members of the statewide transportation steering committee for review and comment, and the questionnaire was presented for suggestions. The questionnaire was further refined to a format that could be administered as a 10-minute telephone survey of overall satisfaction with the transportation system, evaluation of the quality and condition of the system, the importance of different transportation aspects and activities, funding priorities, input into the decisionmaking process, air quality issues, carpooling, and public transportation issues.

\section{Sampling Frame}

Colorado is partitioned into 15 transportation planning regions (see Table 1 for population and sample sizes in each region), and a sampling of 2,020 households (selected by a method that gave all telephone numbers, listed and unlisted, an equal chance of being included) were selected for the statewide telephone survey. Each of the 15 transportation planning regions was represented by a minimum of 100 responses, with metropolitan areas receiving a higher sampling. To ensure maximum control and data accuracy, the questionnaire was in- 


\begin{tabular}{|c|c|c|c|c|}
\hline \multicolumn{5}{|c|}{$\begin{array}{c}\text { Table } 1 \\
\text { Population and Sample Sizes of the } \\
15 \text { Transportation Regions in Colorado }\end{array}$} \\
\hline Region & Population & $\begin{array}{c}\text { Sample } \\
\text { Size }\end{array}$ & $\begin{array}{l}\text { Proportion of } \\
\text { Population (\%) }\end{array}$ & $\begin{array}{l}\text { Prop. } \\
\text { Weight }\end{array}$ \\
\hline 1 & 399,311 & 200 & 0.050 & 1.224 \\
\hline 2 & $1,859,008$ & 500 & 0.027 & 2.280 \\
\hline 3 & 238,542 & 120 & 0.050 & 1.219 \\
\hline 4 & 123,051 & 100 & 0.081 & 0.755 \\
\hline 5 & 93,145 & 100 & 0.107 & 0.571 \\
\hline 6 & 61,924 & 100 & 0.161 & 0.380 \\
\hline 7 & 48,770 & 100 & 0.205 & 0.299 \\
\hline 8 & 52,891 & 100 & 0.189 & 0.324 \\
\hline 9 & 62,091 & 100 & 0.161 & 0.381 \\
\hline 10 & 58,550 & 100 & 0.171 & 0.359 \\
\hline 11 & 83,451 & 100 & 0.120 & 0.512 \\
\hline 12 & 40,988 & 100 & 0.244 & 0.251 \\
\hline 13 & 101,354 & 100 & 0.099 & 0.621 \\
\hline 14 & 51,544 & 100 & 0.194 & 0.316 \\
\hline 15 & 19,774 & 100 & 0.506 & 0.121 \\
\hline Total & $3,294,394$ & 2,020 & 0.061 & \\
\hline
\end{tabular}

corporated into a Computer Aided Telephone Interview (CATI) program. During the survey, repeated attempts were made to contact each of the individuals selected for inclusion in the study to minimize not-at-home sampling frame error.

\section{Results}

Results of the survey were organized by issues (overall satisfaction, quality and condition of the system, etc.). Data were analyzed based on adjusted and unadjusted means. For adjusted means, the proportionate weights were used to adjust for the sample size to population size of each of the regions. Adjusted means represented a sample balanced for the different populations within each 
planning region. Unadjusted means represented a sample giving approximately equal weight to each planning region regardless of its population. However, the pattern of results based on adjusted means was almost identical to that based on unadjusted means. Thus, for presentation purposes, the results based on simple, unadjusted means will be discussed in this paper. Table 2 shows the mean ratings of various transportation service dimensions and issues.

Overall Satisfaction. The overall satisfaction of the public was measured on a 5-point Likert scale ranging from 1 = "strongly disagree" to $5=$ "strongly agree." The respondents were asked to indicate the extent to which they agreed or disagreed with
Table 2

The Public's Ratings of Transportation Services and Issues: Means and Standard Deviations ${ }^{\mathrm{a}}$

Transportation Services/Issues

Mean (SD)

Overall Satisfaction

$2.98 \quad(1.41)$

Quality of the System

Snow Removal

Convenience

3.34

Safety

3.34

Air Quality

3.10

Parking

2.96

Congestion

2.90

Planning \& Design

2.89

Road Conditions

2.74

Repair \& Maintenance

2.71

Importance of Activities

Repair Roads

Improve Air Quality

3.93

Synchronize Traffic Lights

3.87

Increase Incentives for Carpooling

3.60

Increase Capacity of Existing Highways

3.20

Develop New or Better Bus System

3.05

Develop New Light Rail Transit

3.01

Build Carpool Lanes on Major Highways 2.93

Funding Priorities

Potholes

4.15

Elderly/Persons w/ Disabilities Transp.

3.99

Improve/Widen Existing Highways

Timed Stop Lights

3.70

Courtesy Patrols

3.47

3.38

'measured on 5-point Likert scales 
Table 2 (cont)

Transportation Services/Issues

Mean (SD)

Funding Priorities (cont.)

Expanded Bus Service

3.38

Snow Removal

3.36

Sanding

3.30

Rail

3.27

Carpool Lanes

3.13

3.02

New Roads

2.83

Electronic Messages on Highway Signs

Input into Decisionmaking Process

Would Like More Input

Local Officials Provide Opportunity

to Express Opinion

Air Quality Issues

Air Quality Greater Concern

Than Congestion

3.69

Restrict Cars and Trucks That Pollute

3.56

Willing to Pay More for Cleaner Air

Drive Less Because of Air Pollution

3.26

2.66

\section{Carpooling}

Increase Carpool Incentives

(Importance)

Carpool Lanes (Spending)

3.60

3.13

Build Carpool Lanes (Importance)

2.93

\section{Miscellaneous Issues}

Courtesy Patrols Are a Good Idea

\subsection{7}

All Motorcyclists Should be Required to Wear Helmets

4.00

Usually Do Not Feel Safe Riding a Bus
2.94 the statement, "I am satisfied with the level of transportation services in our state." Overall, the average response to the survey suggested that the public was evenly divided into two groups of satisfied and dissatisfied respondents. The average response was 2.98 . The public was almost evenly divided on its level of satisfaction with transportation services in the state. More than 49 percent of respondents indicated they were satisfied with the level of service, while about 44 percent indicated they were dissatisfied. Only a small number of respondents were undecided on the issue.

Quality of the System. One of the major purposes of the survey was to evaluate the public's view of the current condition of the 
state's transportation services. A series of questions asked the public to evaluate the quality of various aspects of the state transportation services on 5-point scales ( 1 = "very poor"; 5 = "excellent"). Most responses centered around neutral. However, some factors were rated as being higher in quality than others. Snow removal, convenience, and safety were rated as being somewhat above neutral. Air quality, parking, and congestion were rated close to neutral, and planning and design, road conditions, and repair/maintenance were rated slightly below neutral.

Importance of Activities. This section of the questionnaire determined the relative importance of transportation service activities. The respondents rated the importance of those activities on 5-point scales from 1 = "not important" to $5=$ "very important." Based on statewide averages, the public rated repairing roads, improving air quality, synchronizing traffic lights, increasing incentives for carpooling, and increased capacity of existing highways as above average in importance. The remaining factors were rated to be of average importance. A strong consensus was demonstrated for the repair and maintenance of roads as the state's chief priority. A substantial majority (61.2 percent) felt that this was very important to the state's agenda.

"Develop new or better bus system" and "develop new light rail transit" both received higher importance ratings than "build carpool lanes on major highways." However, respondents rated "increase capacity of existing highways" higher than the public transportation alternatives.

Funding Priorities. Funding priority questions were essential to finding out the needs and wants of system users. The questions in the previous section asked respondents to rate the importance of certain activities. The questions in this section asked respondents to indicate their opinions about various services on 5-point scales ( 1 = "decrease"; 3 = "maintain at current levels"; 5 = "increase spending"). The public was most likely to support increased spending on pothole repair across the state. This was consistent with the importance of repairing roads in the previous section of the survey. A majority of the respondents (76.1 percent) indicated that spending should be increased for pothole repair. Transporta- 
tion for the elderly or persons with disabilities received the next highest spending increase. Agreement on this issue was widespread among the respondents. Improving/widening existing roads and timing stop lights were activities that also received increased funding support. All activities except electronic messages on highway signs were rated to merit increased levels of spending.

Considering the public transportation alternatives in funding priorities, the public was somewhat favorable towards expanding bus and rail services. The importance for these alternatives was higher than respondents' evaluation for new roads and/or carpool lanes.

Input into Decisionmaking Process. Two questions on the survey dealt with the public's input into the transportation service planning process. Specifically, the public responded on a 5-point Likert scale ( 1 = "strongly disagree"; 5 = "strongly agree") to the statements, "I would like to have more input into transportation decisionmaking than I currently do," and "Local officials provide an opportunity for me to express my opinions about transportation issues." On the average, respondents indicated that local officials provided adequate opportunities for them to express their opinions about transportation issues. However, respondents also said they would like to have more input into the process.

Air Quality Issues. A number of questions dealt with how the public perceived air quality. Respondents seemed to be willing to pay for cleaner air, although there were substantial differences of opinions among respondents. However, respondents indicated a slight unwillingness to drive less because of air pollution.

Carpooling. As previously shown in the sections on important activities and funding priorities of activities and services, there was support for increasing carpool incentives. However, building carpool lanes was not viewed as an important activity, and respondents were only moderately in favor of increasing public spending on this item.

Miscellaneous Issues. In addition to the major categories of findings, other items related to the public transportation services were investigated. In response to the statement, "Courtesy patrols that remove stalled vehicles are a good idea 
to reduce traffic back-ups," the average rating was 4.27 , and 54.4 percent responded with 5 , "strongly agree." However, the section on spending priorities showed courtesy patrols might be an extra amenity people would like to have if more basic activities were accomplished first. Regarding their safety when riding on a bus, respondents, on average, slightly disagreed with the premise, "I usually do not feel safe riding on a bus"; the average rating was 2.94 .

\section{Study 2: Critical Incident and Focus Group Research}

In the second phase of the research project, a series of respondent group meetings was conducted in each of the state's 15 transportation planning regions. The purpose of these gatherings was to meet with those who participated in the telephone survey and to explore significant findings in greater detail. In an informal group setting, respondents were asked about critical service incidents that made them satisfied or dissatisfied with the public transportation system, leading them to discuss other relevant issues. Thus, the methodology utilized in this study was a combination of the critical incident and focus group techniques.

\section{Procedure}

Respondents who were involved in the original telephone survey were invited to participate. Typically, the meetings lasted from 1.5 to 2 hours and were attended by 8 to 12 individuals who resided in the transportation planning region. The questions were derived from the responses to the previous survey and covered topics such as the ratings of transportation service quality, system satisfaction, funding priorities, decisionmaking input, air quality, carpooling, and so forth. At the meeting, participants were presented with regional survey results on these and other topics and asked if they agreed or disagreed with the regional results. The members of the group were asked to explain the regional responses and asked if the responses seemed significantly different from what they would have expected. The purpose of these questions was to determine if the survey responses were valid and to find out why residents from a given region placed more emphasis on one issue over another. 


\section{Data Analysis}

Because of the subjective nature of analyzing the critical incidents and the focus group proceedings, each of the meetings was evaluated and summarized by separate individuals, in an iterative process, to ensure reliability of ratings.

The results of each of the regional group proceedings was viewed by three members of the research team. Each evaluator then developed a list of key issues brought up in the meeting. From that list of key issues, a summary report of the meeting was prepared. After preparing the regional summary report, each of the three reviewers evaluated the summary of the other team members. The group then met to review the findings and to reconcile any discrepancies in the individual summaries. From this, a final report was prepared.

\section{Results}

Overall Satisfaction. One of the primary considerations in satisfaction was effective use of State resources. Participants were most satisfied when they saw the State identifying a problem, allocating resources, and implementing a solution quickly and effectively. A prime consideration was that the State should not have to readdress the same issue year after year; participants believed that doing the job right the first time would free up considerable amounts of transportation revenue and significantly reduce waste. Generally, respondents indicated they were satisfied with most aspects of the system, but were dissatisfied with a few specific items.

Quality of the System. Each group was asked to review the transportation system quality results of its regional survey and to comment on the results. In the telephone survey, residents were asked to rate the quality of items such as snow removal, parking, road conditions, planning and design, and convenience, to name a few. The overall agreement of focus group members with the ranking of important items from the survey was remarkable. Discussions of system quality tended to center around four major topics: repair and maintenance, congestion, air quality, and safety.

Reactions throughout the state favored much better repair and maintenance of the existing road system. The respondents suggested that less money would be 
spent on repairs in the long run if more effort were spent on making repairs properly in the first place. Rather than taking the approach of making less expensive but shorter-lasting fixes to roads, participants indicated they would like to see repairs done right the first time, even if it increased short-term costs. The opinions on repair and maintenance were particularly strong in the more rural areas of the state.

Another issue that arose concerned how increased congestion was affecting the transportation system. Increased congestion was the primary reason for calls to widen and improve existing highways in the state. Congestion was viewed as a contributing factor to safety and air pollution problems. Such concerns about increasing congestion were expressed in the major urban areas as well as in smaller towns that were experiencing growth problems. It is interesting to note that building new roads was not seen as important.

Safety was also identified as a specific problem. While tied to proper maintenance and increasing congestion on the highways, safety was mentioned several times as a specific concern to system users. On a positive note, there was widespread support throughout the state for the quality of snow removal. With very few individual exceptions, focus groups in all the regions indicated that the state did a good job of clearing snow from the roads quickly and efficiently. The only concern raised was the contribution sanding made to air pollution problems.

Importance of Activities and Funding Priorities. Consistent with the survey results, group discussions suggested that the primary areas of public concern were maintaining and improving the existing highway system, better traffic light timing, and better transportation services for the elderly and persons with disabilities.

In the telephone survey, respondents were asked if they would like to see spending increase or decrease for various individual spending items. These items included performing pothole repair, providing transportation for the elderly and persons with disabilities, improving existing roads, building new roads, timing stoplights, providing courtesy patrols, expanding bus service, providing sanding 
and snow removal, installing electronic highway signs, and installing carpool lanes. The result was a list of 11 areas in which respondents indicated funding should be increased. However, group discussions showed that, when presented with such a ranking of items to be given increased funding, residents would give much higher priority to the top two or three items on the list. Therefore, transportation planners should focus on the top few items on the list when evaluating a region's funding priorities.

In most regions, the top funding priorities were either improving/widening existing roads, providing transportation for the elderly and persons with disabilities, timing stoplights, or performing pothole repair. However, in many cases, when pressed to choose the spending alternatives that should receive priority, respondents rated pothole repair below the other top concerns in the region. Even though, ideally, they supported spending increase for many items, they knew they could not afford the new taxes necessary to increase funding for more than a few of the options. One exception to this general observation was the response from a few smaller locales. In these locales, conditions of most items were viewed as being so bad that residents wanted increased spending in nearly every area. The respondents from these locales did not indicate from where they thought additional revenue would be obtained to fund these large spending increases.

With the exception of pothole repair, the other major funding items remained as priorities upon further investigation. This was especially the case regarding increased spending for the elderly and pesrons with disabilities. The reason for the strong support was that people tended to view transportation for the elderly and persons with disabilities as an important service that should be made available by society. It should be noted, however, that citizens generally did not understand the real costs associated with making significant upgrades in the transportation system for the elderly and persons with disabilities.

Other items that were consistently viewed as being the top funding priorities were improving and widening existing highways and providing better traffic light timing. Improving existing highways was identified as a priority to allevi- 
ate congestion and to improve safety conditions. Better timing of traffic lights was given priority because it was viewed as a low-cost solution that could be implemented quickly and easily to alleviate congestion problems.

In major metropolitan areas, in addition to strong support for spending for the elderly and persons with disabilities, one additional priority was increased funding for mass transit projects. In these areas, mass transit was viewed as one of the best ways to reduce congestion and mitigate existing or projected pollution problems.

Input into Decisionmaking Process. Citizens wanted more input in the decisionmaking process if they could be confident that their concerns would be heard. Many indicated a reluctance to get involved in the process because they felt their input would not be taken seriously by transportation officials. From the comments of discussion group members, the best way to increase the amount of public input into decisionmaking seems to be to ensure that people feel their participation in the process actually makes a difference. Rural areas felt left out of the planning process. Citizens in these parts of the state generally felt that State planners ignored their problems and that the State's transportation resources were allocated on an unfair basis. Feelings persisted that urban areas received an undue share of the State's transportation planning and funding resources.

In rural areas, there was a perception that decisionmakers on the state level were not really concerned with their problems and that too much attention was given to the major urban areas. This feeling was also widely held in an isolated area where the public felt disenfranchised from the political and decisionmaking process. There were also calls for the DOT to visit the rural areas of the state and solicit public input. People in such areas even suggested they would support a tax increase to station a DOT representative in the area.

Air Quality Issues. Air quality was often a significant issue during the group discussions. It was linked to concerns about growth, congestion, and support for mass transit. While the level of concern over air quality varied across the state, this issue was raised to some degree by all regions. The participants' judgment of the air quality throughout the state varied, depending on whether they resided in 
urban or rural population centers. In the principal metropolitan areas, there was a strong feeling that mass transit needed to be more fully developed to prevent local air quality from deteriorating any further. In other urban areas, the perception was that air quality was not currently a problem. However, group members were very concerned that, as their areas grew, air quality would degrade significantly and problems would develop. These concerns were so strong that some participants from these areas supported increasing taxes to pay for air quality programs or improving mass transit to keep additional cars off the roads.

The residents of some of the more rural regions also cited air quality as a specific concern. They expressed strong concern that air quality would degrade as traffic and congestion increased with growth and increased tourism. Because air pollution was viewed as being on the increase in these regions, there was also support for increased taxes to pay for air quality improvements or emission inspection programs.

Carpooling. Consistent with the findings from the telephone survey, many participants supported the idea of carpooling as a way to alleviate congestion and pollution problems in the more crowded urban centers. However, the support for carpooling was less strong when addressing specific ways to get more people to use carpools regularly.

In the more rural areas of the state, the perceived benefits of carpooling did not outweigh the additional costs in terms of reduced freedom and personal flexibility. In the urban centers of the state, carpooling was seen as a viable way to reduce congestion problems and to help reduce vehicle emissions.

Most of the suggestions for carpooling incentives centered around tax breaks for businesses that encouraged their employees to use carpools or that provided carpool vans. There was much less support for the building of carpool lanes. Though specified lanes were viewed as an incentive to carpool, the high cost of their construction was the principal reason for the lack of support. This was especially true when the hard costs of building carpool lanes were compared with the less tangible benefits of increased carpooling. 
Overall, respondents viewed the primary incentive for carpooling to be the savings in time and money it would provide to users in crowded traffic areas. They did not feel that other incentives would increase carpooling aside from the personal rewards of reduced vehicle costs and commute times.

Miscellaneous Issues. The following issues were also raised and discussed:

- Bicycles and Highway Safety. Many focus group members were concerned about the increasing number of bicycles on the state's highways. Citizens said the increased number of riders on roads with narrow shoulders posed a safety hazard to bicyclists and motorists alike.

- Vehicle Safety Inspections. Because safety was a strong concern in the state, there were suggestions that one way to improve highway safety would be to resume vehicle safety inspections.

- Highway Rest Areas. Concerns were expressed in several sessions about the need to improve the quality of the state's roadside rest areas. Poor maintenance and the need for additional rest stops were cited as concerns.

\section{Public Transportation}

The support for public transportation came in different forms, depending upon the region and context in which it was presented. In many areas of the state, there was strong support for increasing public transportation. Most of the support was generated by concerns over real or perceived air quality problems, increasing congestion, and the desire to provide adequate transportation services for the elderly and persons with disabilities.

The qualitative research revealed a lack of understanding about the cost of public transportation. In almost every case, the public significantly underestimated the cost of building and operating mass transit systems. This misperception about costs was particularly true regarding the costs of building rail-based mass transit systems. When faced with the choice of mass transit or new roads, the participants opted for mass transit.

Not only was there a misperception about the cost of rail-based mass transit systems, the participants also had little knowledge about the true cost of public 
transportation for the elderly and persons with disabilities, both in metropolitan and rural regions of the state.

Light rail was a subject of many discussions in the areas close to the central metropolitan area of the state. In the focus groups, light rail was viewed as an important contributing solution to the journey-to-work problem in large and medium-sized metropolitan areas. While this method of travel was clearly supported and favored as an alternative, it was apparent that the participants had little understanding of the true development and operating costs of such an alternative. Light rail was viewed as the technological-based solution, complete with savings of time and money that technology brings.

\section{Conclusions}

This research employed a multi-step, multi-method approach to measuring customer perceptions of service quality in the transportation system. The results from the telephone survey (Study 1) and the qualitative research (Study 2) provide significant insights for transportation planners. They also confirm that quantitative and qualitative research techniques should be used in combination for a more accurate picture of customer perceptions and evaluations of service quality.

Study 2 found that the respondents' general level of knowledge about transportation systems might not always be as high as their level of interest in building or using such systems. The study also found that there was a substantial lack of understanding among the public regarding the State funding allocation process-where the funds for transportation came from or how they were allocated. There was a strong reluctance to pay additional taxes until it was clear that the money was not funding individual special projects.

Respondents in both studies indicate they would like to have more input into the transportation decisionmaking process. Transportation planners should consider educating the public on topics such as transportation technologies, building and operating costs, and funding processes. As the public is better educated on transportation issues, they are able better able to make meaningful input into 
the decisionmaking process and, at the same time, take ownership in the overall process. Thus, transportation officials and decisionmakers should make every effort to identify and incorporate public needs and opinions into the planning processes. By using the methodologies developed in this research to measure and track transportation service quality, transportation officials can build a true customer-based system.

The combination of quantitative and qualitative research approaches offers public transportation planners the opportunity to better understand the nature of the support for mass transit and its relationship with public perceptions of congestion and air quality issues. It also allows planners to better understand the nature and strength of the support for alternative public transportation solutions. Armed with this information, public transportation planners can better develop strategies to make the public aware of public transportation alternatives, and also explain the costs and benefits provided by those alternatives.

\section{References}

Bitner, Mary Jo. 1990. Evaluating Service Encounters: The Effects of Physical Surroundings and Employee Responses, Journal of Marketing 54 (April): 69-82.

— Jody D. Nyquist, and Bernard H. Booms. 1985. The Critical Incident as a Technique for Analyzing the Service Encounter, Proceedings of Summer Educators' Conference, Chicago: American Marketing Association: 101-104.

—, Bernard. H. Booms, and Mary S. Tetreault. 1990. The Service Encounter Diagnosing Favorable and Unfavorable Incidents, Journal of Marketing 54 (January): 71-84.

Bolton, Ruth N., and James H. Drew. 1991. A Longitudinal Analysis of the Impact of Service Changes on Customer Attitudes, Journal of Marketing 55 (January): 1-9. Campbell, Donald T., and Donald W. Fiske. 1959. Convergent and Discriminant Validation by the Multitrait-Multimethod Matrix, Psychological Bulletin 56: 81-105. Crompton, John L., and Kelley J. Mackay. 1989. Users' Perceptions of the Relative Importance of Service Quality Dimensions in Selected Public Recreation Programs, Leisure Sciences 11: 367-375. 
Cunningham, Lawrence F., Clifford E. Young, and J. Errett Kroeter. 1994. Developing a Customer Focus in the Statewide Planning Process: A Summary Of Focus Groups, Proceedings of the 74th Annual Transportation Research Board Conference.

-, , and J. Errett Kroeter. 1995. Developing a Customer Focus in the Statewide Transportation Planning Process, Transportation Research Record 1499: 62-69.

—, and Moonkyu Lee. 1996. Determinants of Customer Loyalty to Airline Services: A Critical Review, Transportation Quarterly 50(2): 57-72.

Dunn, Steven C., Robert F. Seaker, and Matthew A. Waller. 1993. Latent Variables in Business Logistics Research: Scale Development and Validation, Journal of Business Logistics 15(2): 145-172.

Fick, Gavin R., and J. R. Brent Ritchie. 1991. Measuring Service Quality in the Travel and Tourism Industry, Journal of Travel Research Fall: 2-9.

Fiske, Susan T., and Mark A. Pavelchak. 1986. Category-Based versus Piecemeal-Based Affective Responses: Developments in Schema-Triggered Affect, in The Handbook of Motivation and Cognition: Foundations of Social Behavior, Richard M. Sorrentino and E. Tory Higgins, New York: Guilford Press: 167-203.

Gourdin, Kent N., and Timothy J. Kloppenborg. 1991. Identifying Service Gaps in Commercial Air Travel: The First Step Toward Quality Improvement, Transportation Journal 31(1): 22-30.

Hopkins, Shirley A., Sandra Strasser, Willie E. Hopkins, and Jerry R. Foster. 1993. Service Quality Gaps in the Transportation Industry: An Empirical Investigation, Journal of Business Logistics 14(1): 145-161.

Jick, T. 1979. Mixing Qualitative and Quantitative Methods: Triangulation in Action, Administrative Science Quarterly 24: 602-611.

Johnson, Linda L., Michael J. Dotson, and B. J. Dunlap. 1988. Service Quality Determinants and Effectiveness in the Real Estate Brokerage Industry, The Journal of Real Estate Research 3: 21-36.

Lee, Moonkyu, Clifford Young, Lawrence Cunningham, and Lee Wadsworth. 1993. Perspectives Regarding Service Quality Measurement in the Airline Industry, Proceedings of the Thirty-Fifth Annual Meeting, Arlington, VA: Transportation Research Forum: 193-201. 
Parasuraman, A., Valarie A. Zeithaml, and Leonard L. Berry. 1985. A Conceptual Model of Service Quality and Its Implications for Future Research, Journal of Marketing 49 (Fall): $41-50$.

— Leonard L. Berry, and Valarie A. Zeithaml. 1991. Refinement and Reassessment of the SERVQUAL Scale, Journal of Retailing 67(4): 420-450.

— - Valarie A. Zeithaml, and Leonard L. Berry. 1988. SERVQUAL: A Multi-Item Scale for Measuring Consumer Perceptions for Service Quality, Journal of Retailing 64(1): 12-40.

Pullen, William T. 1993. Definition and Measurement of Quality of Service for Local Public Transport Management, Transport Review 13(3): 247-264.

Seaker, Robert F., and Matthew A. Waller, and Steven C. Dunn. 1993. A Note on Research Methodology in Business Logistics, Logistics and Transportation Review, 29(4): 383-387.

Smerk, George. 1992. Management of Public Transportation, in Public Transportation, G. E. Gray and L. A. Hoel, Englewood Cliffs, New Jersey: Prentice Hall.

Stank, Theodore P. 1993. Measuring Logistics Service Quality, Journal of Business Strategies, 10(1): 51-62.

Sujan, Mita. 1985. Consumer Knowledge: Effect on Evaluation Strategies Mediating Consumer Judgment, Journal of Consumer Research 12 (June): 31-46.

Weiss, R. 1968. Issues in Holistic Research, in Institution and the Person, H. Becker, B. Greer, and R. Weiss (eds.), Chicago, Illinois: 344-345.

Woodside, Arch G., Lisa L. Frey, and Robert T. Daly. 1989. Linking Service Quality, Customer Satisfaction, and Behavioral Intention, Journal of Health Care Marketing 9 (December): 5-17.

Young, Clifford, Lawrence Cunningham, Moonkyu Lee, and Evan Douglas. 1992. Measuring Airline Service Quality: Preliminary Findings, Proceedings of the International Forum on Airline Quality, Washington, D.C., March 6, 1992.

tive Management Tool: The Case of the Airline Industry, Journal of Marketing Theory and Practice.

Travel Consumer Report From a Customer's Perspective, Journal of Transportation Management 5,1 (Spring): 47-76. 


\section{About the Authors}

Lawrence F. Cunningham is Professor of Marketing and Transportation in the Graduate School of Business at the University of Colorado at Denver.

Cuifford E. Young is Associate Professor of Marketing in the Graduate School of Business at the University of Colorado at Denver.

Moonkyu Lee is Associate Professor of Marketing in the College of Business at Yonsei University in Seoul, Korea. 


\title{
Transit Subsidies in New York and Chicago: Local, State, and Federal Assistance in a Historical Context
}

\author{
Eric Petersen \\ Northwestern University
}

\begin{abstract}
$\overline{\text { Abstract }}$
Nearly all studies of the impact of government subsidies on the transit industry have excluded systems with rail transit. Thus, previous findings cannot simply be extended to transit systems in major metropolitan areas. As a preliminary step in addressing the issue of subsidies and large transit systems, this paper presents historical information on the financial state of the two largest transit systems in the U.S.Chicago's CTA and New York's NYCT. In addition, the subsidies to each system are broken down by level of government-federal, state, and local. The patterns for the two systems are quite different. The CTA remained in relative financial health longer than the NYCT. While the CTA's operating expenses have stabilized recently, its ridership levels (and revenues) have declined sharply. In terms of subsidies, the CTA receives most of these funds at the regional, not state or local, level. In contrast, NYCT's revenues were actually greater in 1995 than they were in 1954 (in constant dollars). However; its operating costs ballooned throughout the 1980s and only recently have been contained. Subsidies to the NYCT come almost equally from state and local sources.
\end{abstract}




\section{Introduction: Issues Surrounding Transit Subsidies}

This paper revisits the issue of mass transit subsidies.' Transit subsidies have been controversial from the inception of the Urban Mass Transportation Act of 1964. Since mass transit is generally viewed as an industry experiencing sharp declines in ridership, but also an industry that still serves essential social functions, people have lined up on both sides of the subsidy issue. Proponents of transit argue that preserving transit is a way of preserving the environment. They also stress relief from traffic congestion as a benefit of continued transit. In general, however, they pay more attention to equity rather than efficiency issues, and their focus is on social, rather than economic, benefits. Others are skeptical that the benefits of transit outweigh the costs of subsidization. In fact, many critics argue that subsidies (particularly operating subsidies) have themselves exacerbated the problem by reducing the productivity of transit systems.

If one does accept the rationales for subsidization, the next issue is whether these transit systems should be supported through capital grants or operating assistance or both. It is worth noting that government assistance for capital improvements has generally been more palatable to politicians, since capital grants are not perceived as open-ended. From the beginnings of federal aid to transit systems, economists warned that providing operating assistance would in essence be opening a Pandora's box, leading to the dissipation of these grants through "labor demands and by wasteful managerial practices" (Hilton 1984: 8). Indeed, operating subsidies were not authorized until 1974 and not without a great struggle on the part of transit advocates in Congress.

In addition, it is also necessary to distinguish between subsidies provided by the different levels of government-federal, state and local. While transit operating subsidies are usually discussed as if they were a purely federal responsibility, there is significant state and local support across the industry (38 percent of total revenues come from fares, 4.5 percent from non-transit sources, 31 percent from local government, 21.5 percent from state government, and only 5 percent from the federal government) (APTA 1996). However, there are wide variations in levels of local support. Smaller systems are typically more depen- 
dent upon federal aid than the aggregate figures suggest. Also, these figures do not include capital grants, where the federal government typically covers 80 percent of the costs.

Indeed, some people might agree that transit merited government support, but that it should be a local, not federal, responsibility. Many argue local government is better able to determine the wishes of the citizenry regarding transit support. The economists Shughart and Kimenyi (1991) believed that imposing more of the burden of financing capital expansion of transit systems on local authorities would result in more realistic projects, as well as more political accountability for transportation decisions. However, when looking at equity concerns associated with subsidies, Pucher and Hirschman (1981) calculated that using federal taxes was a more progressive method overall of financing rapid transit than using local taxes.

Perhaps the most daunting criticism is that transit subsidies have actually worsened the financial situation of mass transit agencies. For instance, Pucher, Markstedt, and Hirschman (1983) calculated that subsidies in and of themselves exacerbated cost increases in rapid transit, particularly labor costs. They criticized the fact that federal transit policy did not tie subsidies to specific goals or to realistic evaluations of transit needs. Shughart and Kimenyi found, like Pucher, Markstedt and Hirschman, that transit costs rose dramatically when federal subsidies were available. Lave (1991) takes a similarly negative view of federal transit subsidies.

This author contends that the subsidy issue is more complex than these studies have indicated. Indeed, the prior studies base their results on aggregate data, obscuring crucial distinctions between systems, such as size. In fact, much research on mass transit specifically excludes agencies that operate rail transit in order to focus on the typical transit agency. While there is some merit in this approach, it is irresponsible to then make sweeping claims about the impact of subsidies. In addition to industry-wide studies, one must analyze individual transit systems and their historical financial performance, particularly in the case of large multi-mode systems. Thus, this paper will present detailed information on 
the financial history, including subsidy levels, of the two largest transit systems in the United States: New York and Chicago. These transit properties are neither typical nor representative of the industry. However, New York City Transit (NYCT) and the Chicago Transit Authority (CTA) are an extremely significant part of the transit picture, together accounting for 27 percent of all transit trips in the U.S.

\section{Subsidies to Transit}

While it is tempting to view transit subsidies as something new, as early as the 19th century, various governmental bodies frequently ceded land for rightof-ways to transportation firms in order to persuade them to build in certain areas. Occasionally, additional land was provided to transportation firms with the intent that they would sell it to finance construction. Then, as now, transportation was viewed as necessary to stimulate regional development and other investment. Canals, railroads, mass transit lines and, of course, the interstate highway system were all built at least partly through government largesse. Even after these initial "capital grants," transportation firms have occasionally been given aid (either state or federal) to carry out specific projects. For instance, in Chicago, the WPA provided much of the funding for the construction of the State Street subway. Several other route extensions received federal funding prior to 1960. This support was not certainly unique to Chicago.

However, this aid had not been part of a systematic federal commitment to mass transit. Federal capital assistance had been somewhat sporadic and not a particularly reliable source of funding. The new era for transit subsidies came in 1964, with the passage of the Urban Mass Transportation Act. It is probably not a coincidence that this new commitment occurred at roughly the same time as the transit industry as a whole went into the red (Hilton 1974). The federal capital program grew rapidly; the cumulative total of federal capital grants from 1961 to 1996 exceeded $\$ 60$ billion.

Federal operating assistance was first authorized in 1974 and was extremely controversial at the time. However, it too became routine. As part of the political balancing act by transit supporters, operating assistance-originally allocated as Section 5 Grants-was split into Urbanized and Nonurbanized Area Formula 
Grants. As critics feared (and proponents hoped) would happen, operating assistance also increased dramatically throughout the 1970s and 1980s. By 1995, the cumulative total appropriations for urban operating assistance alone reached $\$ 16.5$ billion. The commitment to operating assistance has never been particularly strong, however, and federal operating subsidies are slated to be phased out by 1999. It is less clear what will happen to capital subsidies in the future, since transportation funding is supposed to be made somewhat more flexible under ISTEA. The states should be able to allocate their grants between transit and highways in the manner that best suits the needs of their citizens.

Clearly, we are in a new phase in the transit debate, where transit is again conceived of as largely a local responsibility. This will definitely lead to a greater reliance upon state and local sources of subsidy. In major cities with densities that make mass transit feasible, transit service will continue, though it may be scaled back. New York and Chicago, the two largest systems, certainly face a very different set of constraints than do smaller systems. They have farebox recovery rates that hover around 50 percent of operating expenses, but since their expenses are so large compared to the smaller systems, a large commitment from some government source is required to make up the difference.

\section{Financial Data}

The data were gathered primarily from Section 15 Reports or the Annual Reports of the two systems and occasionally supplemented by internal documents from the two systems. The transition from Annual Reports to Section 15 was not perfect. The data in the 1970s (and, indeed, the first few years of Section 15 data) frequently contain questionable values, which have to be checked or calculated from other information. In the Section 15 Reports, fare differentialsoccasionally categorized as revenues and sometimes as subsidies-have simply been included with operating assistance after 1982. This posed a serious dilemma in terms of maintaining consistency. In Figures 1 and 2, fare differentials have been incorporated with operating assistance for all years. In Figures 3 and 4, fare differentials are reported separately until 1982, at which point they are folded 
into the operating assistance from the appropriate governmental body. In effect, fare differentials have been added to state subsidy levels in Chicago and to local subsidies in New York. Finally, the history of New York City Transit makes it particularly difficult to ensure one is measuring the same things every year. Whenever possible, NYCT figures were kept separate from those of its subsidiary, the Manhattan and Bronx Surface Transit Operating Authority. However, these systems appear to have been consolidated in the mid 1980s (in the reports at least), perhaps as the result of another reorganization of the Metropolitan Transit Authority. In likelihood, this accounts for some portion of New York's increasing operating expenses after 1981.

\section{Financial History of the CTA}

The CTA was established in 1945 to take over the provision of transit from several bankrupt transit companies. It began providing service in 1947, after issuing bonds that were to be financed from passenger revenues. In 1952, CTA bought up the local bus company and became the only transit operator in Chicago. It was expected to break even, covering not only its operating expenses but also its debt service requirements (the cost of originally acquiring the cars and rail system). It even paid corporate taxes. CTA remained in financial health much longer than most transit operations, managing to cover operating expenses (though not always its debt service payments) until 1970 . After that, it quickly succumbed to the inflationary pressures that ruined other transit companies around the country.

CTA first received fare differentials in 1965 to make up the cost of reduced fares for students and seniors. It received general operating subsidies in 1971, but apparently did not receive federal operating assistance until 1978 . The state of Illinois has periodically provided grants to pay down much of CTA's debt (essentially making these capital grants). However, it did not want to get directly involved in a perpetual bail-out of the system. Instead, the Regional Transit Authority (RTA) was formed in 1974. The CTA, as well as the suburban bus and rail systems, were placed under the authority of the RTA. The legislature hoped that, by putting transit on a region-wide basis, the provision and funding of mass 


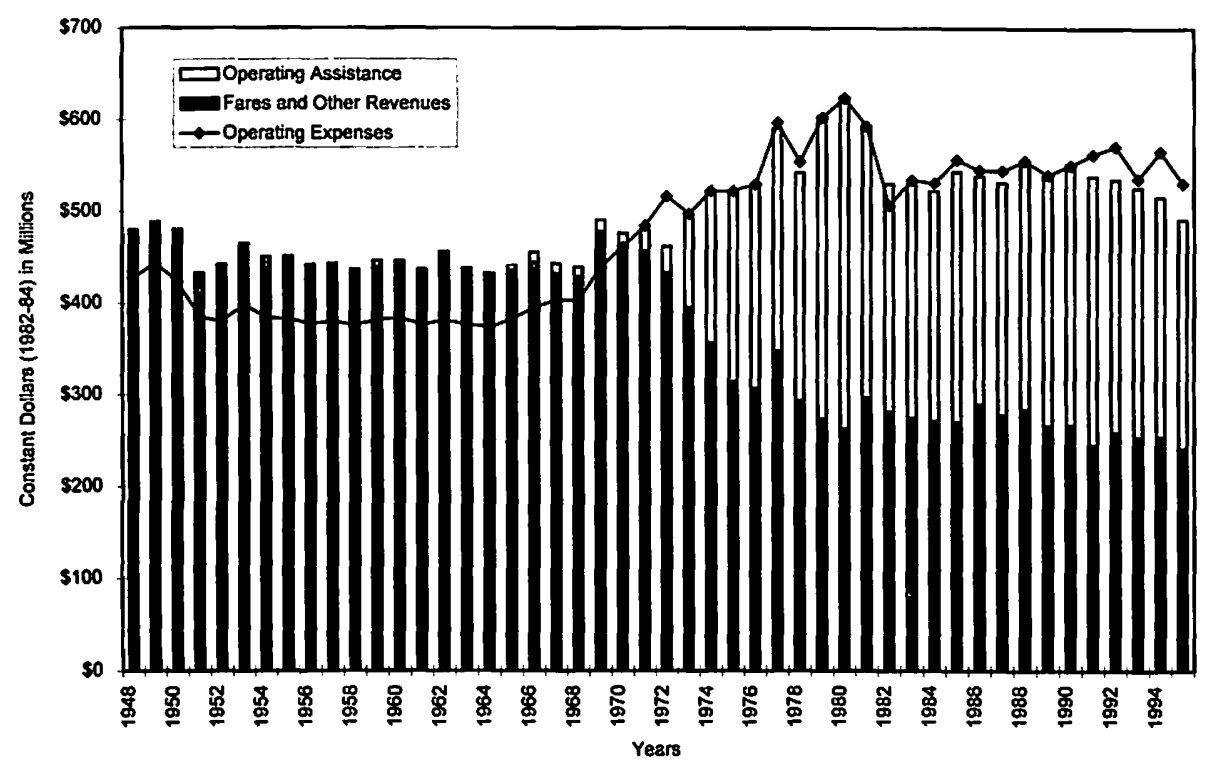

Figure 1. Chicago: Revenue and expenses.

transportation would be stabilized. Even after the creation of the RTA, however, transit operating deficits continued to increase. At several points in the early 1980s, it appeared that CTA would not be able to meet its payroll, and rumors surfaced that CTA would be shut down. In response to this ongoing financial crisis, the RTA itself was reorganized in 1983 (Krambles 1993).

Although the state of Illinois essentially takes a hand-off approach to transit finance, it did set up a sales tax in the six-county Chicago metropolitan region which directly benefits the RTA. In addition, the state provides an additional 25 percent over and above the total revenue collected through the sales tax. These moneys are then allocated to the RTA's service boards (CTA, Metra, and PACE). Thus, the state does provide significant support to mass transit, but in a somewhat indirect fashion. Furthermore, in recent years, the state has not passed the bonds that would have provided matching funds for federal capital grants, adding to the impression that transit in Chicago is a local concern. 


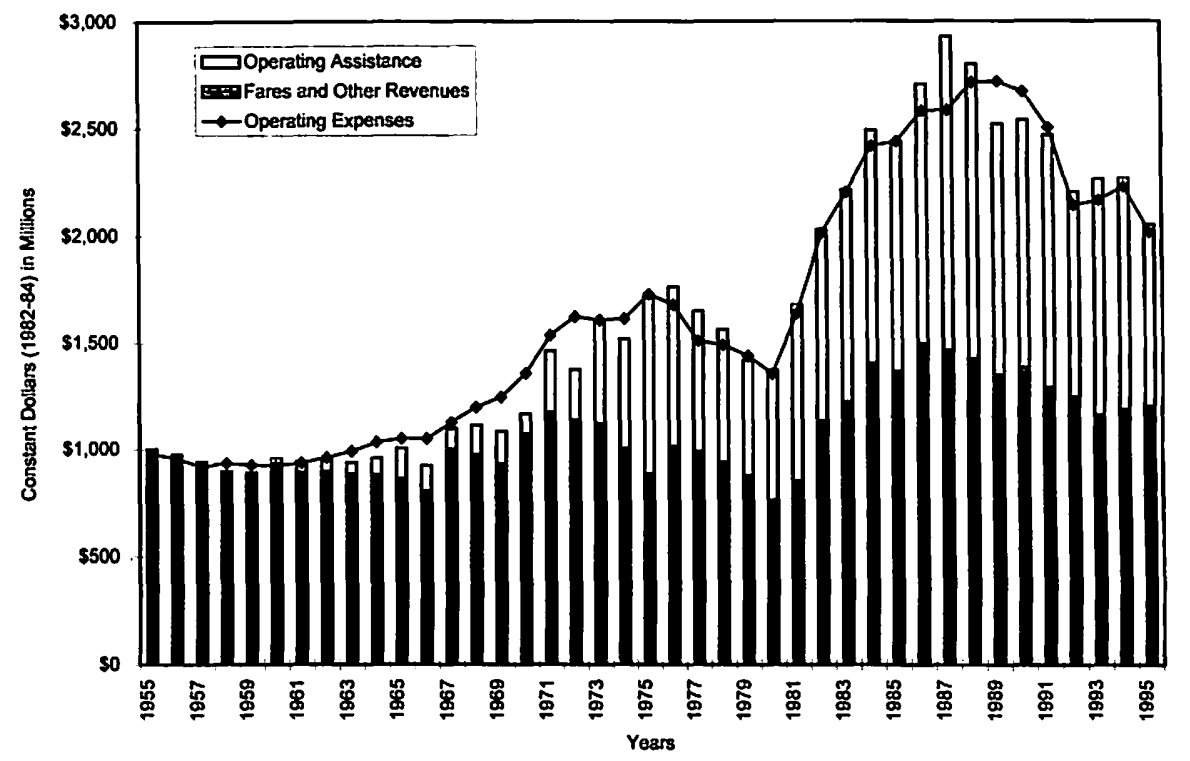

Figure 2. New York: Revenue and expenses.

\section{Financial History of the NYCT}

In contrast to Chicago's relative health, New York City's subways have been in crisis longer. All three subway systems (the private BMT and IRT and, later, the city-run IND) were in severe financial crisis from the 1920s onward. They were municipalized in 1940 under Fiorello La Guardia, who assumed that major efficiencies of scale would be achieved by combining the systems (Hood 1993). Just as in Chicago, NYCT was to be run as a business, with no subsidies provided. Unfortunately, it did not take long for financial problems to resurface, certainly, in part, because City officials still would not allow the fare to rise above a nickel.

New York State reorganized the City's Board of Transportation into the New York City Transit Authority in 1953 (Danielson and Doig 1982). However, because the Authority had no taxing power, this reorganization was of limited use. The State, under Governor Nelson Rockefeller, came up with additional funding for mass transit, including funds for commuter railroads. While this meant the 


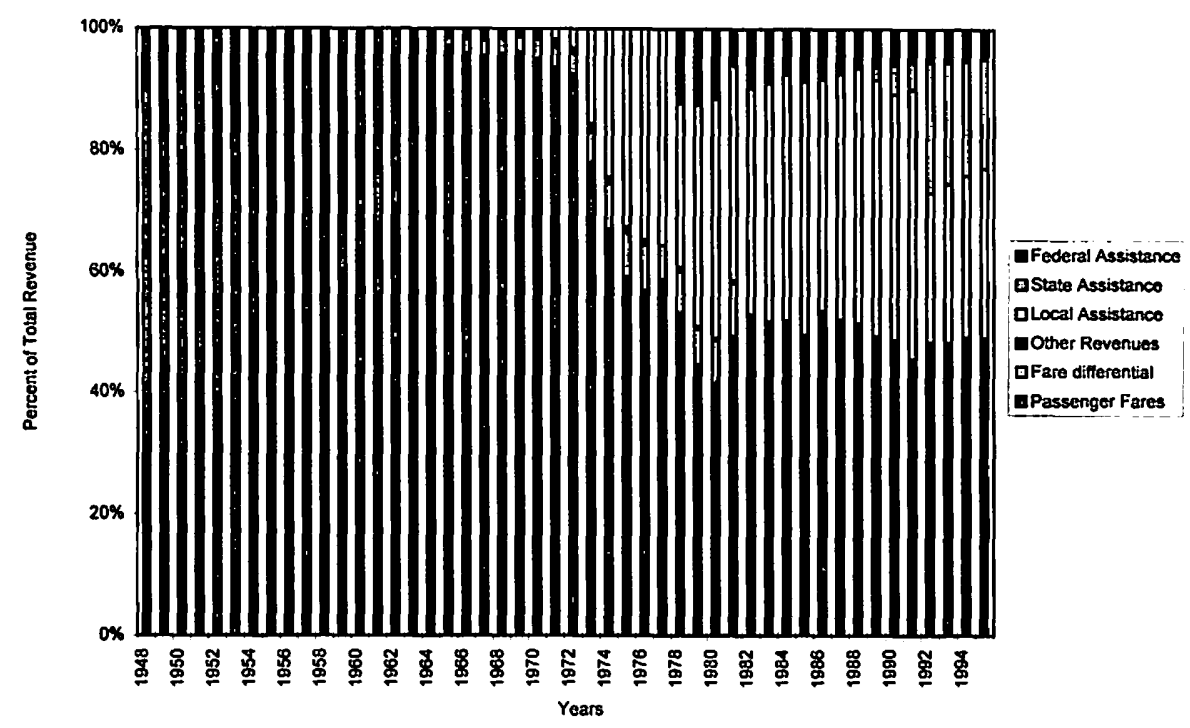

Figure 3. Chicago: Revenue sources.

State was providing some subsidies to New York transit, this was not a stable source of funds. It should be noted that the State (along with the City) has been very involved in New York's transit problems for some time. There is a much closer relationship between the State and the City, though this has been strained from time to time, particularly in recent years. Thus, it is not surprising to find that the proportion of State aid to New York's transit system has consistently been substantial (generally 20 percent).

In 1968, the Metropolitan Transportation Authority (MTA) was created through the merger of NYCT and the Triborough Authority (Danielson and Doig 1982). The Triborough Authority was in much better financial shape and thus was able subsidize transit service. Transit was tied into a regional source of funding for the first time. Furthermore, transportation planning was rationalized and coordinated; problems could be addressed at once, rather than in a piecemeal fashion (Danielson and Doig 1982). 


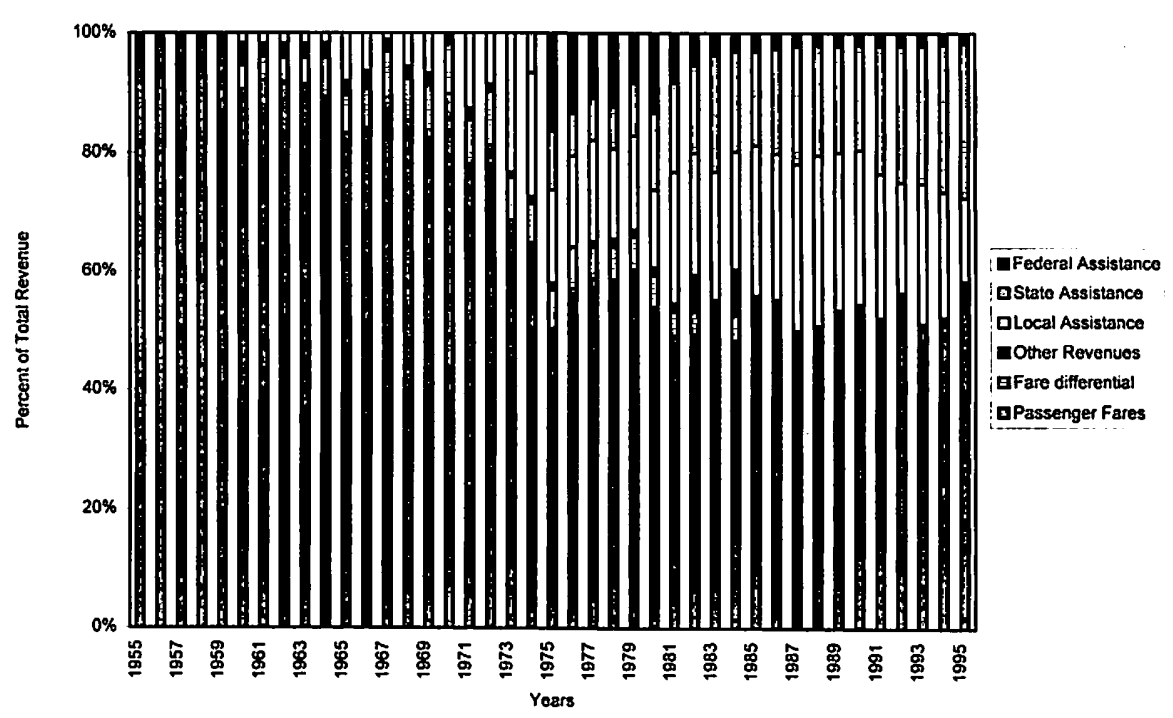

Figure 4. New York: Revenue sources.

Unfortunately, the problems were greater than had originally been imagined. By 1970, the subways were running a deficit of $\$ 120$ million (Danielson and Doig 1982). Governor Rockefeller did not approve of federal-local activities that bypassed the states and was wary of approaching Washington (Danielson 1965). However, City officials felt no such hesitation, and they called upon the federal government for emergency operating assistance (Danielson and Doig 1982). New York received federal operating assistance in 1975 and in every subsequent year. The emergency federal funding became a permanent state of affairs, as many expected it would, though the federal proportion of total revenues has declined greatly over the years.

\section{Analysis of the Systems' Financial Situations}

This analysis of deficits and subsidy levels goes back to the 1947 creation of CTA and the 1953 restructuring of NYCT. ${ }^{2}$ Given how the transit systems have had such different relationships with their respective states, it is hardly 
surprising that the patterns of subsidies for the two systems are very different. CTA has relied much more heavily upon local (or at least regional) financing. It is only in the last few years that State assistance has shown up in their reports, though the true level of State assistance is clearly somewhat higher than in the early Section 15 reports. CTA's reliance on federal funding hovers around 5 percent, which is the same as the industry average.

New York relied on local funding earlier (as far back as 1960). It had received state assistance by 1974 (which, over time, increased to roughly 20 percent of its total revenues) and federal assistance in 1975. After relying very heavily on emergency operating funds from the federal government for several years, NYCT's dependence dropped. Currently, federal assistance makes up only 2 percent of its overall operating revenues. Of course, it is worth noting that, due to its immense size, New York still receives roughly 40 percent more assistance in gross terms than does CTA. (Another way to put the two systems into perspective is to note that New York's state subsidies alone are often larger than Chicago's combined operating revenues.)

It is true that CTA remained in relative financial health for much longer than NYCT. Indeed, CTA was able to meet its operating expenses through passenger revenue until 1971. In the last 20 years, CTA has faced sharp declines in operating revenues in constant dollars, though the operating expenses seem to have more or less stabilized. In contrast, NYCT now has greater revenues than it did in 1954 (in constant dollars). However, its operating costs ballooned throughout the 1980s. While New York has certainly had trouble with its expenses, it appears that it has made dramatic improvements since 1989. By looking at the charts of revenues and expenses, one can identify many of the points at which the systems got into deep trouble. It appears that both systems faced increasing costs in the late 1960s. What might explain such a situation? This period follows the introduction of federal capital subsidies but is before federal operating subsidies were authorized in 1974. If it is true that labor costs were driving the cost increases, then this must have occurred even without the introduction of operating subsidies (or at least federal operating subsidies). One plausible explanation 
is that, in Chicago at least, several route extensions were finally opened up in the late 1960s, including the Eisenhower, Dan Ryan, and Kennedy extensions (Krambles 1993). Of course, these extensions were made possible by the newly available federal capital grants.

However, these years were also extremely bad ones for CTA's ridership. Annual ridership decreased from 510.5 million in 1967 to 457.8 million in 1968. There was an additional 34 million passenger drop the next year (perhaps in part due to a fare increase). The combination of CTA's expansion of its service area with such a sharp drop in its ridership was disastrous. It is hardly surprising that CTA was relying upon general operating assistance by 1971 .

Yet the subsidies were never able to stop the disappearance of CTA's passengers, however. Another large drop occurred between 1980 and 1982, when more than 10 percent of the overall passengers and 15 percent of rail passengers switched to other modes of transportation. Again, it is quite likely that a 50 percent increase in the base fare (from $\$ .60$ to $\$ .90$ ) triggered at least part of this rider flight. To look at the figures in a more positive light, it would be worth investigating how CTA managed to cut its expenses so dramatically in 1980 and again in 1981. The financial reports indicate that there was a savings of $\$ 35$ million in labor costs and associated benefits. If this was a true savings (and not accounting wizardry), one would want to see if it could be replicated. CTA's costs have remained relatively stable since 1985 , so perhaps more attention can now be given to the revenue side.

With respect to the situation in New York, it is clear that their greatest problems were with the cost side and not necessarily with the passenger revenues. Operating costs increased sharply between 1966 (perhaps not coincidentally the year of a major transit strike) and 1975. Suddenly, operating costs decreased sharply. This may have been due to across-the-board service cutbacks and maintenance deferral. In 1980, costs shot up even higher. On the other hand, revenues also made a fairly dramatic recovery. Perhaps these figures reflect the stewardship of David Gunn, who made major improvements during his tenure at the Transit Authority. The costs again decreased from 1989 to 1992, though they 
crept up again in recent years. Operating costs appear to have dropped again in 1995. The reasons for this are unclear.

New York has always had the highest transit share of any city in the U.S., largely due to Manhattan's very high population density and unique geographical features. Transit is essential to New York, and New Yorkers have never been able to completely escape using the subway, even at the times they may have wanted to. New York's transit use patterns have essentially been cyclical, with ridership recovering from periodic declines. While ridership will almost certainly never reach the level of the late 1950s and early 1960s (with 1.8 billion annual passengers), 1995 was the best in several years (with 1.55 billion passengers taking transit). Actually, 1971, 1980, and 1989 were also peak years, much like 1995 was. In each of these years, transit ridership was roughly 1.5 billion passengers. The lowest years occurred in the late 1970s. In 1976 and 1978, ridership was down to roughly 1.3 billion passengers annually. The fact that so many New Yorkers still take transit (in contrast to the severe fall-off in transit use in Chicago) means that fare revenues have remained high. This has been one bright spot in New York's financial picture. In those years that the MTA was able to control costs (such as 1990 and 1991), the operating deficit was significantly reduced.

\section{Expenditure of Operating Funds}

The way that these systems disperse their operating funds is reasonably similar. For both systems, labor is the primary expense. Both systems spend roughly 80 percent on labor, including all salaries and fringe benefits. This has been the case since $1980 .{ }^{3}$ While labor costs were somewhat lower prior to the 1960s, labor has always been the single greatest expense for transit systems. Materials and supplies are generally the next major expense; over the last 17 years, they have averaged 7.5 percent of total operating costs for New York and 10 percent for Chicago. (Of course, the very expensive materials needed for rail reconstruction are accounted for as a capital expense.) Utilities have accounted for 5 percent of New York's operating costs, on average; they have made up 
roughly 4 percent of Chicago's costs. Finally, on average, fuel accounts for only 1 percent of New York's costs, while it accounts for 3 percent of Chicago's costs. This is less surprising when one considers that New York is heavily oriented towards rail transit.

When looking at operating costs by function (and not object class), it is somewhat startling to note that maintenance has been fairly stable. Maintenance is nearly always cut back when budgetary shortfalls occur. Over the last 17 years, Chicago has spent 12.1 percent of its operating funds on non-vehicle maintenance. This amount has been as high as 14.1 percent but never below 10.1 percent (even in 1981, when the system was facing an especially bad fiscal crisis).

In Table 1, in addition to the average for the last 17 years, the average of the last 4 years of available data was included. The reason for this is that the accounting categories for what constituted vehicle operations and general administration was changed. New York dropped from spending fully 30 percent of its operating funds on administration to 11 percent the following year. In order to truly compare the two systems on administrative costs, the last four years seem more relevant. Interestingly, both systems spend almost identical proportions on vehicle operations ( 50.8 percent and 50.6 percent). Looking at the last four years only, Chicago spends more on general administration. In general, Chicago also spends a slightly higher proportion of its budget

\begin{tabular}{|lrr|}
\hline \multicolumn{3}{|c|}{ Table 1 } \\
Proportion of Total Operating Costs \\
\hline & $\begin{array}{r}\text { Average } \\
\text { 1979-95 } \\
\text { (\%) }\end{array}$ & $\begin{array}{r}\text { Average } \\
\text { 1992-95 } \\
\text { (\%) }\end{array}$ \\
\hline New York & & \\
Vehicle Operations & 40.3 & 50.8 \\
Vehicle Maintenance & 19.3 & 17.4 \\
Non-Vehicle Maintenance & 17.2 & 19.3 \\
General Administration & 23.1 & 12.1 \\
& & \\
Chicago & & \\
Vehicle Operations & 51.0 & 50.6 \\
Vehicle Maintenance & 20.1 & 20.0 \\
Non-Vehicle Maintenance & 12.1 & 13.2 \\
General Administration & 15.5 & 13.5 \\
\hline
\end{tabular}


on vehicle maintenance and less on non-vehicle maintenance than does New York. Again, this is consistent with the CTA being a bus-oriented agency.

\section{Other Financial Issues}

This paper has largely focused on operating subsidies, in part because they are particularly controversial and the funding patterns are so different among various systems. ${ }^{4}$ With capital grants, federal funding is by far the most important source across all systems. However, the distinction between operating and capital funding is somewhat arbitrary. While the distinction certainly has real consequences for transit systems, funding categories can and do shift, generally for political reasons.

Often higher levels of government change the rules for transit agencies. This may mean that an "inviolable" transportation trust fund is tapped into during a severe fiscal crisis. Similarly, promised funds may not be available. On the other hand, a state or federal agency may make funding more flexible, so that transit agencies can allocate resources according to their needs. This is the intent of ISTEA.

However, not all funds can be "flexed" between categories. Both CTA and NYCT have deferred some kinds of maintenance in favor of shorter term operating functions. This is one way of moving capital funds over to cover operating expenses. Programmed federal funds, especially for "New Starts" cannot be moved about so cavalierly. Unfortunately, even after the implementation of ISTEA, the funding structure for transit subsidies continues to demonstrate a bias in favor of system expansion rather than system maintenance. Given that operating subsidies are being zeroed out, transit operators are forced to devise strategies for obtaining capital funding from Washington. In essence, they are looking for a "capital fix." One result of this is that transit operators defer maintenance until a portion of the system has to be reconstructed-and thus is eligible for federal support. This is basically what occurred on Chicago's Green Line, which recently reopened. The strategy is a perfectly rational one, given that transit systems operate in a resource-constrained environment. Unfortunately, the cost of 
reconstruction is almost always much higher than what was "saved" by deferring maintenance. Indeed, this strategy is not limited to transit operators. Most state highway departments are forced to adopt the same tactics, given the capital bias in federal funding (Sanders 1995). Making transit funds more "fungible" would help avoid these inefficiencies. However, given the chronic shortfall in operating funds, transit systems are likely to divert capital funds to operations when possible. This is a historic pattern, going back to the original owners of private transit systems. Thus, a complete analysis of transit funding would have to look at the amounts of capital funding channeled to operations, though determining the exact amounts is very difficult, given the nature of the financial portion of older annual reports. At present, this information has not been compiled.

\section{Points for Further Research}

Further research into transit subsidies and productivity is necessary before one could conclusively demonstrate that it was the subsidies (either operating or capital) that accelerated the financial crises of the transit industry in the 1970s and 1980s. In order to fully test this hypothesis, one would first need to collect several other performance measures, including passenger miles, revenue miles, and number of employees. In addition, one would need to determine the metropolitan population, number of private automobiles (to measure the competition), strike activity, and the price of labor, fuel, and capital over these years. Of course, one would also need to determine capital funding (and diversions of capital funding) as well. This extension of the research is currently under way. Still, the historical financial information by itself is crucial for determining the major fluctuations in the financial situation of either system, which, in turn, will allow transportation experts to focus their attention most intently upon these crucial moments.

\section{Endnotes}

1 This is a revised version of a paper presented in Chicago at the May 1997 Metropolitan Conference on Public Transportation Research. The author wishes to thank Prof. Ian Savage and two anonymous readers for comments on this paper, as well as the 
staff of Northwestern's Transportation Library for their assistance in the data collection process.

${ }^{2}$ Since the first year of operation for each system was only a partial year, this data was not included in any charts.

${ }^{3}$ All information in this section comes from Section 15 Reports and thus only covers FY 1979 to 1995.

${ }^{4}$ This section, along with additional material on operating expenses, was added on the recommendation of an anonymous reviewer.

\section{Acknowledgments}

This is a revised version of a paper presented in Chicago at the May 1997 Metropolitan Conference on Public Transportation Research. The author wishes to thank Prof. Ian Savage and two anonymous reviewers for comments on this paper, as well as the staff of Northwestern's Transportation Library for their assistance in the data collection process.

\section{References}

Altshuler, Alan A. (with James P. Womack and John R. Pucher). 1979. The Urban

Transportation System: Politics and Policy Innovation. Cambridge, MA: MIT Press.

APTA. 1996. APTA Transit Fact Book. Washington D.C.: APTA.

Chicago Transit Authority. Annual Reports.

Danielson, Michael N. 1965. Federal-Metropolitan Politics and the Commuter Crisis.

New York: Columbia University Press.

Danielson, Michael N., and Jameson W. Doig. 1982. New York: The Politics of Urban Regional Development. Berkeley, CA: University of California Press.

Frankena, Mark W. 1982. The Justification for Transit Subsidies. Chapter 5 in Urban Transportation Financing: Theory and Policy in Ontario. Toronto, University of Toronto Press.

Hilton, George W. 1974. Federal Transit Subsidies: The Urban Mass Transportation Assistance Program. Washington, D.C.: American Enterprise Institute for Public Policy Research.

Hood, Clifton. 1993. 722 Miles: The Building of the Subways and How They Transformed New York. New York: Simon \& Schuster. 
Jones, David W., Jr. 1985. Urban Transit Policy: An Economic and Political History. Englewood Cliffs, NJ: Prentice-Hall, Inc.

Krambles, George, and Art Peterson. 1993. CTA at 45: Recollections of the First 45 years of the Chicago Transit Authority. Oak Park, IL: George Krambles Transit Scholarship Fund.

Lave, Charles. 1991. Federal Subsidies and the Ruinous Decline in Transit Productivity: It Wasn't Supposed to Turn Out Like This. Berkeley, CA: Transportation Center, University of California.

Metropolitan Transit Authority. Annual Reports.

New York City Transit Authority. Annual Reports.

Pucher, John, and Ira Hirschman. 1981. Distribution of the Tax Burden of Transit Subsidies in the United States, Public Policy 29 (3): 341-367.

Pucher, John. 1983. Distribution of Federal Transportation Subsidies: Cities, States, and Regions, Urban Affairs Quarterly 19 (2): 191-216.

Pucher, John, Anders Markstedt, and Ira Hirschman. 1983. Impacts of Subsidies on the Costs of Urban Public Transport, Journal of Transport Economics and Policy 17 (2): 155-76.

Regional Transit Authority. 1996. 1997 Annual Budget and Five-Year Program. Chicago: RTA.

Sanders, Heywood T. 1995. Public Works and Public Dollars: Federal Infrastructure Aid and Local Investment Policy, in Building the Public City: The Politics, Governace, and Finance of Public Infrastructure, Urban Affairs Annual Review 43, David C. Perry, ed., Thousand Oaks, CA: SAGE Publications.

Shughart, William F., and Mwangi S. Kimenyi. 1991. Public Choice, Public Subsidies, and Public Transit, Washington, DC: Urban Mass Transportation Administration.

U.S. Conference of Mayors. 1979. Transit Financing: An Overview of the National Transit Financing Picture in Terms of Federal and State Funding Levels, Fare Structures and Local Revenue Sources, Washington D.C: U.S. Department of Transportation.

Wachs, M. 1985. The Politicization of Transit Subsidy Policy in America, in Transportation and Mobility in an Era of Transition, Gijsbertus R.M. Jansen, et al., eds., Amsterdam: Elsevier Science Publishers. 
Womack, James P., and Alan A. Altshuler. 1979. An Examination of the Transit Funding Process at the Local Level. Cambridge, MA: Center for Transportation Studies.

\section{About the Author}

Eric Petersen is a graduate student in the Transportation Center at Northwestern University, as well as in the Sociology Department. In addition to studying mass transit subsidies, he has written on reverse commuting programs, the group dynamics of international travelers, and the politics of urban transportation planning. 


\title{
Evaluation of Automatic Vehicle Location Technologies for Paratransit in Small and Medium-Sized Urban Areas
}

\author{
Gary S. Spring \\ North Carolina A\&T State University \\ John Collura \\ Kenneth B. Black \\ University of Massachusetts
}

\begin{abstract}
This paper presents an evaluation framework designed for small and mediumsized city automatic vehicle location (AVL)-based paratransit systems and describes the application of that framework to one such paratransit system in North Carolina. Issues addressed include the benefits of implementing AVL, whether AVL for paratransit can be used effectively in small to medium-sized cities, and the problems associated with implementing such technologies. The paper is meant to provide guidance for other similar AVL evaluation efforts. A controlled before and after study approach is used to evaluate the AVL system in the City of Winston-Salem, North Carolina (population 265,878). Key findings are that the paratransit system's efficiency improved slightly with AVL but that demand variables did not change significantly relative to non-AVL equipped vehicles. Reasons for this outcome are examined.
\end{abstract}




\section{Introduction}

\section{Background}

Intelligent Transportation Systems (ITS) include a range of technologiessuch as automatic vehicle location systems (AVL), on-board guidance systems, electronic payment systems, automated control systems, and crash avoidance systems. These technologies hold great promise for increasing operational efficiency and safety of public transit systems. The Americans with Disabilities Act of 1990 includes requirements for complementary paratransit systems that can respond to previous-day reservations and that could lead to provision of realtime scheduling and dispatch. Operational pressures, such as vehicles operating at 25 percent or lower capacity, and subsidized costs of carrying passengers that sometimes exceed twice the fare of comparable taxi service are additional indicators of existing inefficiencies.

In response to this need, the Federal Transit Administration (FTA) has made the applications of ITS technologies to public transit a priority through its Advanced Public Transportation Systems (APTS) program. As with ITS in the highway arena, the application of APTS technologies offers potential in improved operational efficiency, lower costs, and enhanced system effectiveness. This paper presents an evaluation framework designed to assist in the assessment of small and medium-sized city AVL-based paratransit systems. The paper illustrates the application of the framework using one such paratransit system in Winston-Salem, North Carolina. The design and application of the framework are consistent with FTA's APTS Evaluation Guidelines (Casey and Collura 1993) and will be of interest to transit planners and managers in small and mediumsized cities. It is hoped that this information will be useful as a guideline for other similar efforts.

\section{Automatic Vehicle Location (AVL)}

As the name implies, automatic vehicle location devices provide location information about vehicles automatically. There are several different approaches 
for accomplishing this, some quite old (land-based systems) and some fairly new (satellite-based systems).

\section{Land-Based Systems}

Land-based AVL technology has been used by railroads in some form since the late 19th century, whereas the application of AVL to local transit began in the 1980s. These systems are of limited use for variable route, demand response systems, however, because they cannot track vehicles that are not on course, with the exception of Loran $C$ where topography permits, as explained below. The most common types of systems include dead reckoning, Loran $\mathrm{C}$, sign post and radio/cell phone. A brief description of each is provided below.

Dead Reckoning. Probably the oldest of the location methods, dead reckoning was the navigational system used by early sailors to determine location on the open sea. It involves traveling in a known direction at a known speed for a measured time interval (on transit systems, the odometer is used for distance determination rather than the speed and time measures). Given the distance traveled, the direction traveled and the position of the starting point, a new location can be calculated. The method has serious limitations. The first is that errors accumulate. Small errors in each leg of a trip result in significant positional errors at the final destination-thus requiring that accurate intermediate locations be established along the route. Second, accurate distance measurements are critical. Yet, the accuracy of the accumulated mileage on a bus route is only as accurate as the bus odometer which is on the average around $+/-2$ percent (100 feet on a 20-mile bus route). Third, accurate direction is difficult to obtain. Usually, the magnetic compass in the bus must be initialized and is easily influenced by local attraction (NIACAD 1991).

Loran $C$. Originally developed for maritime applications, Loran-C is a long range, signal-triangulation navigation system. It operates using a system of government-run radio transmission sources and was initially developed for use by ships and aircraft. Radio signals are received from three or more transmitters whose locations are known. The location of the receiver can be calculated using triangulation techniques. The transmitters must be in the direct line of sight of 
the receivers; therefore, Loran- $C$ positioning is severely limited by topography. Given this limitation and the fact that the technology is being phased out with the advent of global positioning systems (GPS), it is, again, of limited use for transit applications (Smith 1990).

Sign Post. The railroad industry has used sign post technology for years. The technology consists of devices along fixed routes that recognize when a vehicle passes them and communicates that information to a central dispatching office. Although expensive, due to the significant amount of infrastructure required, sign post technology has been used for fixed route transit. It is not, however, applicable to demand response systems such as paratransit because of the fixed nature of the infrastructure (Labell 1992).

Terrestrial Radio/Cell Phone. These consist of a set of fixed receivers that receive signals from a vehicle's radio or cell phone and subsequently calculate the vehicle's position by triangulation. This requires that specialized infrastructure be built. It is of limited use for variable route systems due, again, to the fixed infrastructure requirement.

\section{Satellite-Based Systems}

The most common type of satellite-based systems is the global positioning system. A brief description is provided below.

Global Positioning Systems (GPS). A space-based system of artificial satellites and ground receivers, global positioning systems provide location in three dimensions. The system currently has 27 satellites in place. Receivers obtain signals from four or more satellites to calculate their position using triangulation. The system was created and originally used by the U.S. Air Force Space Command. It is now being used extensively for civilian applications. Due to the selective availability of the satellites, location accuracy using affordable receivers is around 50 to 100 feet-certainly adequate for AVL transit applications (Kavanagh 1996). The more expensive differential GPS systems, providing accuracies up to the nearest centimeter, are not necessary for this application. 


\section{Description of the Winston-Salem Paratransit System}

The Winston-Salem Transit Authority (WSTA), with more than 150 vehicles, provides fixed-route, modified fixed-route, downtown circulation, fringe park and shuttle, park and ride, demand responsive paratransit, contract paratransit, vanpools, carpool matching, and vehicle brokerage services. WSTA serves the City of Winston-Salem and surrounding counties.

Trans-AID is WSTA's paratransit, dial-a-ride service and serves the city of Winston-Salem and Forsythe County (1990 population 265,878). Trans-AID serves approximately 800 passengers per day with its 17 paratransit vehicles and currently runs a geographic information systems (GIS) based automated scheduling and dispatching system (Stone et al. 1996). WSTA, along with the North Carolina Department of Transportation, FTA and others, funded a Mobility Management Project whose purpose is to "provide human service agency passengers, commuters, and the general public with 'one stop shopping' for multimodal public transportation" (Stone et al. 1996). The potential of GIS/AVL for intermodal connections was not examined as part of the study since it was beyond the study's scope. WSTA wants this new system to serve as a test-bed for evaluating advanced technologies. As part of a pilot study, it purchased GPS units, mobile data terminals (MDT) and smart cards for three of its paratransit vehicles. The equipment was installed at the beginning of June 1995.

\section{Description of AVL-Based Paratransit Systems}

There are a great number of transportation applications for which AVL may be (and often is) profitably applied, including emergency response, truck and bus fleet management, and paratransit systems. The generic AVL-based paratransit system consists of a device to determine a vehicle's location, some sort of communication device in the transit vehicle and in the dispatch office, GIS software to display location information, and scheduling and dispatching software to provide the capability to use the location information.

WSTA's system uses GPS for location, MDTs and radio for communication, and a MapInfo-based scheduling and dispatching software package (PASS). Radio communication is accomplished using a radio "trunking" system, which 
is essentially a "time share" of air space and, thus, does not require purchase of a dedicated radio frequency. For the purposes of this paper, the term AVL is used to represent this combination of equipment.

\section{Rationale and Significance of Study}

\section{Problem Statement}

Central to the ability of APTS to improve paratransit efficiency is the improvement of the process of dispatching and scheduling demand-responsive transportation. The manner in which vehicles and trips are matched directly affects passenger service levels and system productivity. Locating shared-ride transit vehicles in real time is key to success in this regard. At the beginning of a typical paratransit tour, a pre-arranged schedule is given to each driver which lists the sequence, pickup times, addresses and destinations of its passengers as well as directions for minimum time or distance paths to follow. This scenario does not lend itself to real-time operation. Using automatic vehicle location (AVL) technology, each vehicle's location is known at any point in time and, with the integration of GIS technology, may be displayed on a map display at the control center. The AVL, along with the GIS database linked to customer information would facilitate real time requests for service-perhaps, initially, providing sameday service, gradually approaching real-time service. The AVL/GIS would allow insertions for "will calls" (unscheduled return trips) to be made more efficiently as well. Additionally, with in-vehicle displays (such as MDTs), the driver's schedule may be stored in digital form and could be updated as necessary.

\section{Advantages of AVL-Based Paratransit}

The potential advantages of AVL vis á vis paratransit, in terms of increased operational efficiency, effectiveness and safety can be significant. Real-time information about vehicle location would:

- provide the capability to coordinate paratransit with fixed route facilities-thus reducing operating costs;

- allow same-day scheduling, approaching real-time response;

- $\quad$ provide improved service potential (more timely, more flexible, etc.); 
- enhance driver and passenger safety/security; and

- provide information for personnel management programs.

Of course, effective use of the AVL-provided information requires a graphical display such as that provided by geographic information systems. This combination of technologies offers many potential benefits to paratransit operators. In the near term, operators would be able to observe system performance in real time and make immediate adjustments where necessary, potentially avoiding service delays. Service could then be more responsive to travelers' demands rather than scheduled a day or more in advance. The potential for improved efficiency of scheduling and dispatching using the AVL/GIS-provided information would provide better and less expensive service. This would encourage increased ridership, thus increasing operational effectiveness of the system as well. Another, somewhat less tangible but nevertheless very real, benefit would be the capability of sending assistance to the location of an emergency signal transmission which could save lives where voice communication may not be possible. For the long term, knowledge-based decision support systems would observe system performance and respond more quickly and efficiently than the human operator is currently able, thus improving operational efficiency even more.

These advantages are well recognized and many paratransit properties in the United States are planning implementation of an AVL system in the very near future (Spring et al. 1995). There exists, therefore, a critical need for a methodology to evaluate these systems.

A survey of paratransit properties across the U.S. (Spring et al. 1995) regarding AVL-based paratransit evaluation found that only one system, Houston's MetroLift, has progressed far enough in its implementation of AVL on paratransit to be able to conduct an evaluation. That system is a relatively large one and serves a major city.

The potential advantages of AVL-based paratransit, coupled with the fact that no other efforts have been made to evaluate an AVL-based paratransit system in a small or medium-sized city, have shaped the objective for this paper, 
which is to develop and illustrate the use of an evaluation framework to assess AVL systems on paratransit services in small and medium-sized urban areas.

\section{Research Approach}

The general approach taken for the Trans-AID evaluation was that of the pilot study, where a subset of information was used to demonstrate how a new technology may be used to solve a particular problem or problems and to identify implementation problems. The City of Winston-Salem was chosen as the pilot site for several reasons:

- It had already implemented scheduling and dispatching software.

- It was willing and able to serve as a test bed.

- It had requisite software (PASS, which is a GIS-based automated scheduling and dispatching package), and had AVL units on three of its paratransit buses.

Key study questions of interest in the evaluation were:

- What are the benefits of implementing AVL?

- Can AVL for paratransit be used effectively in small to medium-sized cities?

- What are the problems associated with implementing such technologies?

\section{Experimental Design}

To evaluate the effectiveness of AVL operation, a "before and after" study was performed on the WSTA system in which non-AVL operation (before period) was compared to AVL operation (after period) using a set of efficiency and effectiveness evaluation criteria. There are several serious disadvantages to the standard before and after study (Hummer 1994), which were addressed as part of the current study's experimental design. First, after "treatment" (in this case, installation of the AVL units) there exists a period of adjustment during which data should not be used. AVL units were installed in May 1995 on three WSTA paratransit vehicles. Data for the "after" period began in September 1995, which allowed in excess of three months for the adjustment period. A second disadvantage to the approach concerns changes in evaluation measures caused by factors 
other than the treatment (Council et al. 1980). This was addressed in two ways: both the "before" and "after" periods were selected during the same time of year (September-October time frame); and, the "before period" was chosen so that it fell well after implementation of scheduling and dispatching software but before installation of the AVL. The third, and most difficult, is the so-called "maturation" problem - that is, changes in evaluation measures may be due to pre-existing trends in the variables used. The second and third issues were addressed using a "controlled" experiment. Given that WSTA chose to install AVL on only three of its 17 vehicles, it was possible to perform a controlled experiment using a control group (the non-AVL equipped vehicles) and a treatment group (AVLequipped vehicles). Percent changes in measures rather than absolute changes from before and atter were compared. For example, the percent change in numbers of passenger trips per vehicle hour from the "before" to the "after" period was calculated for both the control and treatment groups. The "hours of service" variable was calculated using elapsed time from first pick up of the day to the last drop off. These changes were statistically tested to determine whether they were significantly different from one another. Figure 1 depicts the situation.
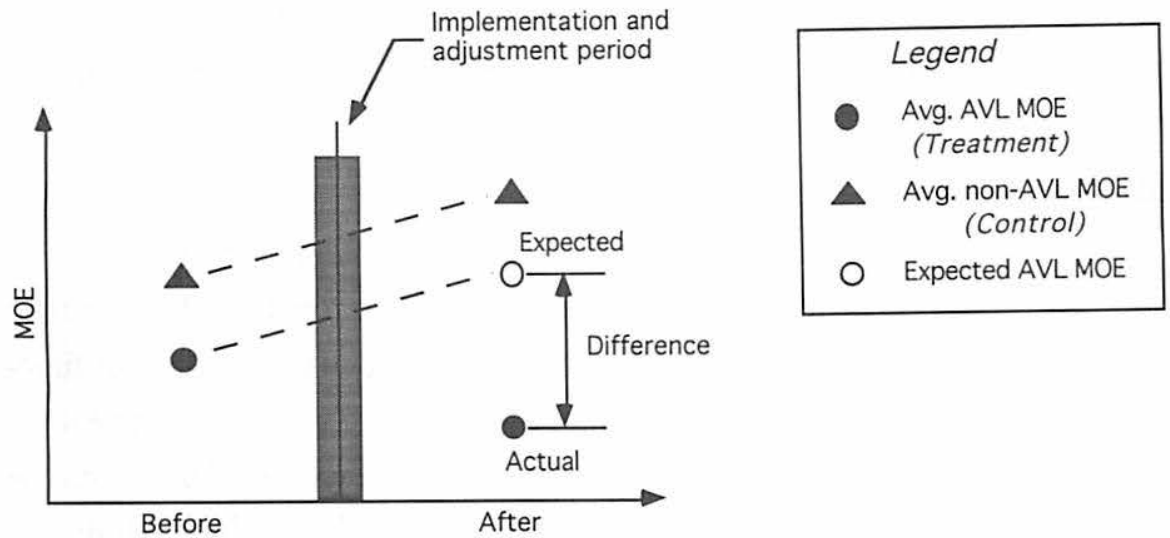

Figure 1. "Before" and "after" with control. 


\section{Data Collection}

The City of Winston-Salem's current paratransit activities were characterized. Details regarding current hardware and software capabilities, personnel, bus fleet, ridership figures, driver logs, and so on, were collected as part of this task. Data from the PASS-generated driver log files were used in developing measures of effectiveness (MOE) for the project. Each day, a driver log dBase file with 65 fields was generated by the PASS software. For the "before" period, data from files for October 3, 1994, through October 31, 1994, were used to create MOE values. Only weekday operations were considered. For the "after" period, data from files for September 11, 1995, through October 6, 1995, were used. Each data file contains approximately 900 records, one for each passenger trip served that day. Variables extracted from the files are:

RIDERS

CAPICALC

CAPCALC

COLLECT

NEGETA
Number of passenger trips for the day

Number of passengers with special needs

Bus occupancy

Time of day that driver actually completed pick up or drop off

Negotiated pick up/drop off time of day

Aggregate values of these variables were calculated for each day and entered into a summary file. Each day, representing between 800 and 900 entries, constitutes one record in the summary file.

\section{Evaluation Framework}

The FTA guidelines for evaluating advanced technologies mentioned earlier (Casey et al. 1993) were used as a guide for this evaluation. Measures of effectiveness were identified in an attempt to capture as many of the four functional areas defined in the APTS Guidelines as possible. Figure 2 lists the MOEs used and indicates in which functional evaluation area each lies. Data from the PASS-generated driver log files were used to calculate MOE values. MOE values, for "before" and "after" implementation of the AVL, were used for evaluation. 


\begin{tabular}{|c|c|c|c|c|c|}
\hline \multirow[b]{2}{*}{ Name } & \multirow[b]{2}{*}{ Description } & \multicolumn{4}{|c|}{$\begin{array}{c}\text { Performance } \\
\text { Dimension }\end{array}$} \\
\hline & & 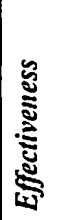 & 忥 & : & 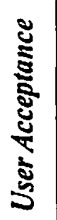 \\
\hline Pass Trips & $\#$ of passenger trips (per day) & $\checkmark$ & & & $\checkmark$ \\
\hline SP Needs Patrons & \# of patrons with special needs served & $\checkmark$ & & & \\
\hline Bus Occupancy & Bus occupancy & $\checkmark$ & & & \\
\hline Pass Trips per Veh-Hr & \# of passenger trips per vehicle hour & $\checkmark$ & & & \\
\hline Time Deviation & pickup time agreed vs pickup time provided & & $\checkmark$ & & \\
\hline
\end{tabular}

Figure 2. Evaluation matrix.

\section{Discussion of Results}

All variables were tested for normality. It was found that there is not enough statistical evidence at the 95 percent confidence level to say that they are not normally distributed. Table 1 provides a summary of normality test results. However, the type of test to which the variables were subjected is a "robust" test

\begin{tabular}{|lccc|}
\hline \multicolumn{4}{c|}{$\begin{array}{c}\text { Table 1 } \\
\text { Tests for Normality }\end{array}$} \\
\hline \multicolumn{1}{|c}{ Variable } & $\chi^{2}$ & $\chi^{2}$ Critical & Result \\
\hline Passenger Trips & 48.52 & 51.00 & Normal \\
Special Needs Patrons & 26.05 & 31.41 & Normal \\
Bus Occupancy & 98.54 & 101.88 & Normal \\
Passenger Trips/Vehicle Hour & 13.60 & 26.30 & Normal \\
Time Deviation & 37.45 & 59.30 & Normal \\
\hline
\end{tabular}


(Kachigan 1982) and, therefore, the assumption of normality for all variables was a valid one.

Entries in Table 2 were calculated in the following ways:

- $\% \Delta$ for nonAVL and AVL groups was calculated by subtracting the average "before" for the individual parameter from its respective "after" value and dividing by the "before" value. Equation 1 illustrates the process:

$$
\% \Delta_{A V L \text {-or-nemAVL }}=\frac{\chi_{\text {Afler }}-\chi_{\text {Befine }}}{\chi_{\text {Befine }}} \times 100 \%
$$

Eq. 1

\begin{tabular}{|c|c|c|c|c|c|c|}
\hline \multicolumn{7}{|c|}{$\begin{array}{c}\text { Table } 2 \\
\text { Summary of Results }\end{array}$} \\
\hline & & Trips & $\begin{array}{c}\text { Special } \\
\text { Needs } \\
\text { Patrons }\end{array}$ & \multicolumn{2}{|r|}{$\begin{array}{c}\text { Trips } \\
\text { per } \\
\text { Veh. Hr. }\end{array}$} & $\begin{array}{l}\text { Time } \\
\text { Dev. }\end{array}$ \\
\hline \multirow[t]{2}{*}{ NonAVL } & $\% \Delta$ & $40 \%$ & $28 \%$ & $28 \%$ & $55 \%$ & $76 \%$ \\
\hline & $\mathbf{s}$ & $20 \%$ & $30 \%$ & $28 \%$ & $31 \%$ & $69 \%$ \\
\hline \multirow[t]{2}{*}{ AVL } & $\% \Delta$ & $-24 \%$ & $-18 \%$ & $-17 \%$ & $-13 \%$ & $26 \%$ \\
\hline & $\mathbf{s}$ & $61 \%$ & $64 \%$ & $59 \%$ & $74 \%$ & $102 \%$ \\
\hline \multirow[t]{2}{*}{ Difference } & $\% \Delta$ & $-63 \%$ & $-46 \%$ & $-45 \%$ & $-67 \%$ & $-50 \%$ \\
\hline & $s_{e}$ & $15 \%$ & $17 \%$ & $16 \%$ & $19 \%$ & $30 \%$ \\
\hline \multirow[t]{2}{*}{ Hypotheses: } & $t$ & -4.08 & -2.68 & -2.84 & -3.45 & -1.66 \\
\hline & $t_{90}$ & -1.75 & -1.75 & -1.75 & -1.75 & -1.34 \\
\hline \multirow[t]{2}{*}{ Ho: $A V L=$ NonAVL } & $t_{95}$ & -2.13 & -2.13 & -2.13 & -2.13 & -1.75 \\
\hline & $t_{99}$ & -2.95 & -2.95 & -2.95 & -2.95 & -2.60 \\
\hline \multirow[t]{3}{*}{ Alternatives: } & AVL & AVL & AVL & AVL & AVL & AVL \\
\hline & $<$ & $<$ & $<>$ & $<>$ & $<$ & $<$ \\
\hline & AVL & NonAVL & NonAVL & NonAVL & NonAVL & NonAVL \\
\hline
\end{tabular}


- Standard deviations for the two groups were calculated using equation 2 shown below (Kachigan 1982).

$$
\mathrm{s}=\sqrt{\mathrm{s}_{A}^{2}+\mathrm{s}_{A}^{2}-2 \mathrm{rs}_{A} \mathrm{~s}_{B}}
$$

where:

$\mathrm{S}_{A}=$ standard deviation of the "after" period

$\mathrm{s}_{B}=$ standard deviation of the "before" period

$r=$ the correlation coefficient between the "before" and "after" groups.

- $\quad \% \Delta$ for the "Difference" group was calculated by subtracting the nonAVL $\% \Delta$ from the AVL $\% \Delta$. Equation 3 illustrates the process:

$$
\% \Delta=\% \Delta_{A V L}-\% \Delta_{n u n A V L}
$$

The standard error term for the above difference value was calculated using equation 4 , shown below:

$$
s_{x / c}^{2}=(1 / c)^{2} s_{x}^{2}
$$

where $c=\bar{\chi}_{\text {Before }}$ used in equation 1 .

Each MOE was subjected to the following hypothesis test:

Ho: $\% \Delta=0$

Ha: $\% \Delta \neq 0$ (for Time Deviation: $\% \Delta<0$ )

Therefore, all were 2-tail tests with the exception of Time Deviation. The Student's t-distribution was used for the tests with 15 degrees of freedom (each group had 17 observations). The t statistic was calculated by dividing $\% \Delta$ by the 
$\mathrm{s}_{\mathrm{e}}$ value. Critical values for 90 percent, 95 percent and 99 percent confidence levels are shown in Table 2.

Table 2 indicates that neither non-AVL-equipped nor AVL-equipped vehicles changes in the "before" and "after" periods are significantly different from 0 (all $t$ values, although not shown, are less than the critical $t$ for 95 percent) yet differences in percent change from before and after periods are significant for all MOEs.

The time deviation MOE, an efficiency measure, shows the AVL equipped buses performed better (at the 90 percent confidence level)-i.e., the reduction in time deviation is for those vehicles significantly greater than that for the nonAVL-equipped vehicles. This is not surprising, given the nature of AVL. The dispatcher is better able to do insertions, for example, which would reduce time deviations.

A reasonable explanation, perhaps, for why the AVL showed no improvement in the demand-related effectiveness variables, yet did indicate improvement for the efficiency MOE, is that the AVL would need to be implemented on the whole system before the improvements in service could be expected to affect demand. Users may not perceive the improvements in efficiency, especially if the same buses are not used consistently by the same patrons.

\section{Conclusions and Recommendations}

The City of Winston-Salem's Trans-AID system, as part of a pilot study, installed and implemented AVL devices on three of its 17 vehicles. The system's MDT-AVL equipment was evaluated using a "before and after" experimental design. Findings indicate that the AVL devices have led to an improvement in the efficiency performance measure (time deviation). None of the effectiveness or user acceptance measures showed any statistically significant improvement over the non-AVL-equipped vehicles. It was postulated that this may be due to the short time during which the AVL has been implemented and to the fact that only three vehicles were AVL-equipped. It seems reasonable that demand-related measures would not improve unless all vehicles were so equipped and a longer time were observed. 


\section{Major Conclusions}

The evaluation framework may be used by small and medium-sized city paratransit systems for their AVL systems to answer several questions, including those posed at the outset:

- What are the benefits of implementing AVL?

- Can AVL for paratransit be used effectively in small to medium-sized cities?

- What are the problems associated with implementing such technologies?

Costs and Benefits of Implementing AVL. Not surprisingly, an outcome of this study indicates that operation efficiency can improve with the use of AVL, even with minimal use of AVL technology (only 3 of 17 vehicles were equipped with AVL equipment and the GPS portion of the AVL was used only minimally for insertions, although MDTs were used extensively). This can result in reductions in deadhead miles that may allow the operator to provide more service. Other potential benefits which might follow are demand-related, such as increased ridership and occupancy. These measures did not increase as expected, as stated earlier, perhaps because the AVL devices were not implemented on a wide enough basis (i.e., on the whole system).

Although initial equipment and set up costs can be high $(\$ 15,000)$, per-unit costs are only about $\$ 3,000$ for each vehicle and are expected to come down. These per vehicle costs include mobile data transfer units, GPS units, modems and software. This does not include the cost of a dedicated radio frequency, which is quite substantial. This, however, given recent advances in "piggy-backing" technology, may not be an issue in the near future.

Effectiveness of AVL for Paratransit for Small to Medium-sized Cities. Although the demand-related measures normally associated with effectiveness showed no improvement, it may be concluded that AVL use did improve the effectiveness of the WSTA paratransit system. Effectiveness means that the system has attained a desired effect. One desired effect of a paratransit system is improved service to its riders, whether or not they are able to perceive that im- 
provement. The system's service did improve significantly, as evidenced by the changes in time deviation.

Problems Associated with Implementing Such Technologies. AVL requires that several issues be resolved for its successful implementation. First, it requires a radio frequency for communicating vehicle positions from the MDT in the vehicle to the dispatcher. The WSTA system used a trunking system, which is essentially a time-sharing system with other users of the radio frequency. Access to the frequency is therefore limited, which could lead to positional accuracy problems. For example, if polling is limited to every three minutes, a vehicle could easily travel one to two miles from the position relayed. Second, users (passengers and clients) must perceive that they are reaping benefits from the use of AVL, and drivers and dispatchers must accept and use the AVL devices. Third is a study design issue. Although equipping a small subset of vehicles introduces problems, the controlled approach explained here is superior to the standard "before and after" study. The extreme changes in variables from before to after in the control (unequipped) group, described in Table 2, support this statement.

\section{Recommendations}

Several recommendations can be derived from this study. First, and perhaps most important, is the evaluation study design used, that is, a controlled "before and after" design. The controlled experiment examines differences in changes from before to after for each group. It therefore accounts for changes in evaluation measures that may have been due to pre-existing trends in the variables used or other outside influences on the system that may cause system changes in performance. Presumably, the control and treatment groups are both subject to these trends/influences. One would therefore expect that changes in their performance variables would not be significantly different-statistically speaking. Of course, this study was limited, in that only three of 17 vehicles were equipped with AVL, and no control was imposed on them in terms of service area. A better design would include a longer time frame, perhaps half the vehicles equipped with AVL, and more control over each group's service area — thus providing more 
consistent before and after data. It is recommended that future evaluations of AVL for paratransit adopt the controlled experiment approach for the reasons outlined previously. Second, the type of location technology recommended for paratransit operation is the satellite-based GPS. Reasons for this include:

- Paratransit's routes continually change, suggesting that the location system should not require a fixed, land-based infrastructure to operate.

- In small to medium-sized urban settings, GPS is typically more reliable than in large urban settings, where tall buildings sometimes create problems.

- The locational accuracy required is provided by the lower-end GPS units, so costs are less an issue.

- GPS does not require infrastructure other than the satellites already in place. The satellites are accessed free of charge and require no maintenance on the part of the agency.

- Finally, GPS is an emerging technology; it is anticipated that its use will continue to increase.

Third, it is suggested that a dedicated radio frequency is an extremely valuable characteristic of an AVL system. As indicated earlier, WSTA's trunking system is less than optimal. For example, for insertion purposes if polling occurs every three minutes, a vehicle could be 1.5 miles or more away. *

\section{Acknowledgment}

The authors thank Trans-AID staff at the Winston-Salem Transit Authority, whose active participation and amiable cooperation were key to the project's success. The authors also thank Dr. John Stone and Mr. Peter Gray-Mullen at North Carolina State University for their willingness to share data and ideas. This work was sponsored by the Urban Transit Institute at North Carolina A\&T State University. 


\section{References}

Casey R.F., and J. Collura. 1993. Evaluation Guidelines for the Advanced Public Transportation Systems Operational Tests, U.S. Department of Transportation, Federal Transit Administration, Report Number DOT-VNTSC-FTA-93-9, Washington D.C. Council F. M., et al. 1980. Accident Research Manual, U.S. Department of Transportation, Federal Highway Administration, Report Number FHWA/RD-80/016, Washington D.C.

Hummer J. E. 1994. Experiment Design, Manual of Transportation Studies, Appendix A, Institute of Transportation Engineers, Englewood Cliffs, NJ: Prentice-Hall. Kachigan S. K. 1982. Multivariate Statistical Analysis, New York: Radius Press.

NIACAD. 1991. AVL Technology Investigation and Applicability Report, prepared for PVTA, Ontario, Canada.

Kavanagh B. F. 1996. Surveying Principles and Applications, 4th Edition, Englewood Cliffs, NJ: Prentice Hall: 446-454.

Labell L. N., C. P. Schweiger, and M. Kihl. 1992. Advanced Public Transportation Systems: The State of the Art Update 1992, U.S. Department of Transportation, Federal Transit Administration, Report Number DOT-VNTSC-FTA-92-3.

Smith, T. 1990. A Guide to Loran Technology, Alpha Resource Inc (Company Literature), October: 76.

Spring G.S., J. Collura, and K. B. Black. 1995. Evaluation of Automated Vehicle Location Technologies Used In Automatic Scheduling \& Dispatching Systems for Small Urban Areas in North Carolina, Final Report to the Urban Transit Institute, North Carolina A\&T State University.

Stone J. R., and P. Gray-Mullen. 1996. Winston-Salem Mobility Management: An Evaluation of Computer-Aided Dispatch and Scheduling, Transportation Research Board, preprint for 1996 Annual Meeting.

\section{About the Authors}

Gary S. Spring is an Associate Professor in the Department of Civil Engineering at North Carolina A\&T State University.

John ColluRa is a Professor in the Department of Civil and Environmental Engineering at the University of Massachusetts, Amherst.

KenNeth BLaCK is a doctoral candidate in the Department of Civil and Environmental Engineering at the University of Massachusetts, Amherst. 


\title{
Design and Development of a Bus Stop Inventory to Support an Intelligent Transportation System: The MARTA Experience
}

\author{
Wayne Sarasua \\ Georgia Institute of Technology \\ Robert Awuah-Baffour \\ Bradley University \\ Mark Fawley \\ $T R W$ \\ Carlton Byars \\ MARTA \\ Jeffery Orton \\ Utah Transit Authority \\ $\overline{\text { Abstract }}$
}

Bus stops are a critical element in any transit system. The advent of Intelligent Transportation System (ITS) technologies in the area of transit has developed a need for transit agencies to keep an up-to-date inventory of bus stop data. Unfortunately, 
most transit agencies do not have a bus stop inventory that can adequately support Advanced Public Transportation System (APTS) applications, and many other transit agencies do not have an inventory at all. The design, development, and maintenance of a bus stop inventory that will support an array of available APTS applications is described in this paper. Procedures used in the development of the Metropolitan Atlanta Rapid Transit Authority bus stop inventory are highlighted. The lessons learned from MARTA's experience should be valuable to other transit agencies that are planning to or are in the process of implementing an APTS.

\section{Introduction}

In the spring of 1995, the Metropolitan Atlanta Rapid Transit Authority (MARTA) contracted with a team of consultants and researchers to implement an Intelligent Transportation System (ITS). The purpose of this system was to create a showcase of technology for the 1996 Summer Olympic Games and to leave MARTA with a legacy that would improve transit performance and increase ridership in the long term. The project put in place at MARTA three areas of technology: 1) Advanced Traveller Information Systems (ATIS) that provide an automated means of assisting MARTA patrons with travel information, 2) Automatic Vehicle Location (AVL) for tracking bus positions in real time, and 3) an interface with Georgia Department of Transportation's Advanced Transportation Management System (ATMS) so that up-to-date traffic and road condition information could be made available to MARTA.

At the core of the MARTA ITS is a series of spatial and attribute databases that provides critical information to all of the different ITS applications. One of the transit features that is described in these databases is the bus stop. Bus stop data are of particular importance to the MARTA ITS because they are used by so many different applications. The attribute data associated with each bus stop is as extensive as any other bus stop inventory that currently exists in the United States. The database contains more than 60 fields that provide detailed location information and the physical characteristics of the bus stop and the surrounding area. 
This paper describes the design, development, and maintenance of the bus stop inventory that supports MARTA's ITS. The procedures described in this paper should be applicable to other transit agencies implementing systems that fall under the Federal Transit Administration's Advanced Public Transportation Systems (APTS) Program (Casey et al. 1996).

\section{APTS Applications Supported by a Bus Stop Inventory}

The design of a bus stop inventory database is driven by the applications that it will need to support. The two primary ITS applications that depend on bus stop information at MARTA are:

- $\quad$ ATIS, which provides an automated means of assisting MARTA patrons with travel information, and

- AVL which provides real-time bus locations.

Bus stops are fundamental to the MARTA ATIS. MARTA's ATIS provides a patron with an itinerary that includes a description of the bus stops at the beginning and end of a trip, as well as bus stops at any transfer points. MARTA has found that many patrons ask specific information about bus stops such as whether or not the bus stop is sheltered or lighted or if the stop is wheelchair accessible. These attributes, as well as many others, are available to the patron through the ATIS. Bus stops are also an important component of the AVL. As a bus nears a particular bus stop, the on-board Global Positioning System (GPS) provides a central computer with the bus location. This location is matched with a bus stop through coordinate matching. Details of the approaching bus stop are relayed to passengers through an automated announcement. Another AVL application is automatic passenger counting. The number of passenger alightings and boardings can be matched with the corresponding bus stop using the same matching process that is used for bus stop announcements.

Several other uses of bus stop data that do not fall under the ITS umbrella include transportation planning, maintenance, and information management. 
MARTA's bus stop database includes a series of fields to support these applications as well.

\section{Bus Stop Inventory Database Design}

The considerations in designing a bus stop database include identification of fields, the types of fields (e.g., character, integer, date, etc), the size of the fields, the allowable range of values (e.g., 0 - 200), and the relationships between the bus stop table and other database tables in the overall system. Further, it may be necessary to have multiple tables to manage just the bus stop data. An example would be if a particular field has, say, six discrete choices. The bus stop type field is an example. Let us assume the possible values for the bus stop type field are post, strap sign, pedestal sign, shelter, paint, and station. If the inventory procedures require typing in a value for the field, it may be preferable to use a code $(1,2,3,4,5$, or 6$)$ to represent the above choices. Thus, the user would simply have to type in " 3 " rather than "pedestal sign" for each bus stop of this type. This example can be managed in a relational database by creating a separate table that includes the codes and associated descriptions. A relational join could then be set up between the master bus stop table containing only the codes and the separate table containing the code definitions.

The database that supports the MARTA ITS applications includes more than 30 relational tables. Twelve of these tables are at least partially maintained within the Geographical Information System (GIS). Figure 1 provides an EntityRelationship (E-R) diagram of these tables. The largest of the tables shown in Figure 1 is the stop master table, which contains the bus stop data. This table currently includes 66 fields and more than 10,000 records. An identification number (stop ID) serves as a unique key that makes it possible to link bus stop data with data in other tables, such as those associated with time points and routes.

Table 1 provides a list of 36 fields that pertain to the actual field inventory. The inventoried fields in the stop master table include identification fields, coordinate fields, street location fields, fields describing the physical characteristics of the bus stop, and fields describing the surrounding area. The stop master table 


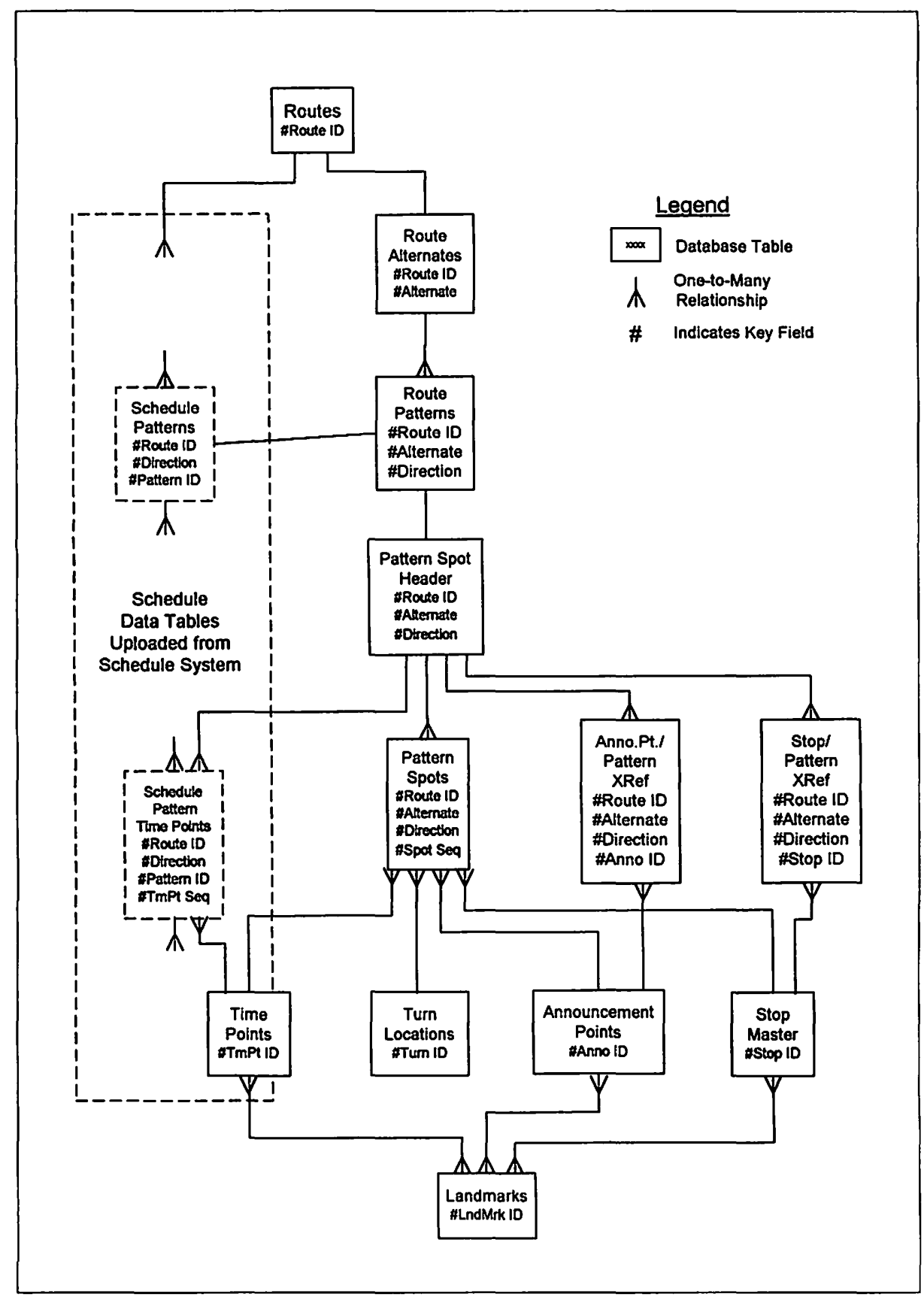

Figure 1. Entity-relationship diagram of GIS-maintained tables. 


\section{Table 1}

\section{Bus Stop Inventory Database Contents}

\begin{tabular}{|c|c|c|}
\hline Field & WidthType & Description \\
\hline stop_id & 8 chars & $\begin{array}{l}\text { Unique ID for each bus stop, based on grid cell } \\
\text { location. }\end{array}$ \\
\hline description & 35 chars & Description of where the bus stop is located. \\
\hline building_no & 10 chars & $\begin{array}{l}\text { Address of the bus stop on the "on" street (requires } \\
\text { AT or OP). }\end{array}$ \\
\hline on_street_prefix & 2 chars & $\begin{array}{l}\text { Prefix of the street the bus stop is on (values: N, S, } \\
E, W \text { ). }\end{array}$ \\
\hline on_street_name & 20 chars & Street name where bus stop is located. \\
\hline on_street_type & 4 chars & $\begin{array}{l}\text { Type of street the bus stop is on (e.g., Ave., Dr., } \\
\text { etc.) }\end{array}$ \\
\hline on_street_suffix & 2 chars & $\begin{array}{l}\text { Suffix of the street the bus stop is on (values: N, S, } \\
E, W \text { ). }\end{array}$ \\
\hline on_street_dir & 2 chars & $\begin{array}{l}\text { Direction of travel of the "on" street (values: N, W, } \\
E, W, N E, N W, S E \text {, or SW. }\end{array}$ \\
\hline intersection_pos & 2 chars & $\begin{array}{l}\text { Position on the "on" street relative to the "at" street } \\
\text { (values: NS, FS, MB, AT, OP). }\end{array}$ \\
\hline at_street_prefix & 2 chars & Prefix of the "at" street which the bus stop is near. \\
\hline at_street_name & 20 chars & Name of the "at" street which the bus stop is near. \\
\hline at_street_type & 4 chars & $\begin{array}{l}\text { Type of the "at" street which the bus stop is near } \\
\text { (similar to on_street_prefix). }\end{array}$ \\
\hline at_street_suffix & 2 chars & $\begin{array}{l}\text { Suffix of the "at" street field which the bus stop is } \\
\text { near (similar to on_street_type). }\end{array}$ \\
\hline bet_street_prefix & 2 chars & $\begin{array}{l}\text { Prefix of the between street which the bus stop is } \\
\text { near. }\end{array}$ \\
\hline bet_street_name & 20 chars & Name of between street which the bus stop is near. \\
\hline bet_street_type & 4 chars & Type of between street which the bus stop is near. \\
\hline bet_street_suffix & 2 chars & $\begin{array}{l}\text { Suffix of the between street which the bus stop is } \\
\text { near. }\end{array}$ \\
\hline dist_from_at_st & Small int & $\begin{array}{l}\text { Distance of the bus stop from the "at" street in feet } \\
\text { (values: } 0-50,50-200,>200 \text { ). }\end{array}$ \\
\hline
\end{tabular}


Table 1 (cont)

\begin{tabular}{|c|c|c|}
\hline Field & Width/Type & Description \\
\hline comment & 30 chars & $\begin{array}{l}\text { Any comment related to the bus stop. This field is } \\
\text { optional. }\end{array}$ \\
\hline ada_accessibility & 1 char & $\begin{array}{l}\text { Accessibility of bus stop by elderly persons or per- } \\
\text { sons with a disability (values: yes } Y ; \text { no } N \text { ). }\end{array}$ \\
\hline sidewalk & 2 chars & $\begin{array}{l}\text { Sidewalk? (Values: yes Y; yes but poor condition } \\
\text { YP; yes but short YS; no N). }\end{array}$ \\
\hline lift & 2 chars & Can a handicap lift be used? (values: yes $\mathrm{Y}$; no N). \\
\hline curb & 2 chars & $\begin{array}{l}\text { Curb at the bus stop? (values: yes Y; yes but not lift } \\
\text { accessible } Y N \text {; no N). }\end{array}$ \\
\hline curb_cut & 2 chars & $\begin{array}{l}\text { Denotes a curb cut (values: yes Y; no N; not appli- } \\
\text { cable NA). }\end{array}$ \\
\hline telephone & 1 char & $\begin{array}{l}\text { Nearby telephone? (values: none N; public P; busi- } \\
\text { ness B). }\end{array}$ \\
\hline park_and_ride & 1 char & $\begin{array}{l}\text { Is bus stop located at a park and ride facility? (val- } \\
\text { ues: yes Y; no N). }\end{array}$ \\
\hline bus_stop_type & 3 chars & $\begin{array}{l}\text { Bus stop type (post POS; strap STR; shelter SHM; } \\
\text { paint PNT; sign SGN). }\end{array}$ \\
\hline neighborhood & 3 chars & $\begin{array}{l}\text { Land use nearby (commercial COM; school SCH; } \\
\text { industrial IND; mix MIX). }\end{array}$ \\
\hline lighting & 1 char & $\begin{array}{l}\text { Type of lighting at the bus stop (values: dedicated } \\
D ; \text { poor P; on-street OS). }\end{array}$ \\
\hline landmark & 40 chars & The largest landmark serviced by the bus stop. \\
\hline latitude & Float & Latitude value for bus stop; collected by GPS. \\
\hline longitude & Float & Longitude value for bus stop; collected by GPS. \\
\hline collect_date & 10 chars & Date bus stop data collected. \\
\hline
\end{tabular}

includes several additional fields that are generated by the GIS and other programs that process the inventoried bus stop data. Some examples of generated data include the city, county, and zip code in which the bus stop is located. A GIS point-in-polygon operation is used to provide these data. 


\section{Assigning Unique Bus Stop Identifiers}

A unique bus stop identification scheme was needed to serve as a key to the bus stop data. Several schemes were considered, including assigning random IDs, assigning IDs by route, and using a grid cell scheme. The random ID was undesirable because there would be no logical consistency between bus stops in close proximity to one another. Assigning bus stops by using the route ID in the bus stop ID was not feasible because many bus stops serve more than one route. The scheme ultimately chosen for the MARTA ITS was a grid cell system. DeKalb and Fulton counties (the two counties served by MARTA) were divided into 200 distinct grid cells. Any bus stop falling in a particular grid cell received an ID of $X X X Y Y Y$, where $X X X$ is the cell number and $Y Y Y$ is the bus stop sequence number within each cell. The benefit of this identification scheme is that ID numbers are consistent with nearby bus stops. The grid cell system that was used for the MARTA ITS is shown in Figure 2.

\section{Cartesian and Two Sets of Geographic Coordinates}

The MARTA ITS required using three pairs of coordinate fields. To support the third party trip itinerary software, cartesian coordinate fields were needed. This was purely a function of the third-party software and may not be required for other jurisdictions. Geographic coordinates (longitude and latitude) were required to support the AVL application. These coordinates need to be reasonably accurate. This is especially important for the automated passenger counters and the bus stop announcements. The third pair of coordinates is longitude and latitude as related to the underlying base map. These may vary from the true geographic coordinates, depending on map accuracy. The need for this third pair of coordinates is discussed in the following paragraph.

Most of the bus stops in the MARTA service area are within 100 feet of an intersection and many are within a few feet of an intersection. In the collection process using differential GPS, the expected accuracy of the bus stops is within 10 feet. If the underlying GIS map at a particular intersection provides less than 20-foot accuracy, the bus stop could easily appear to be on the wrong side of the street on the GIS map. The user has one of three options: 1) do nothing; 2) edit 


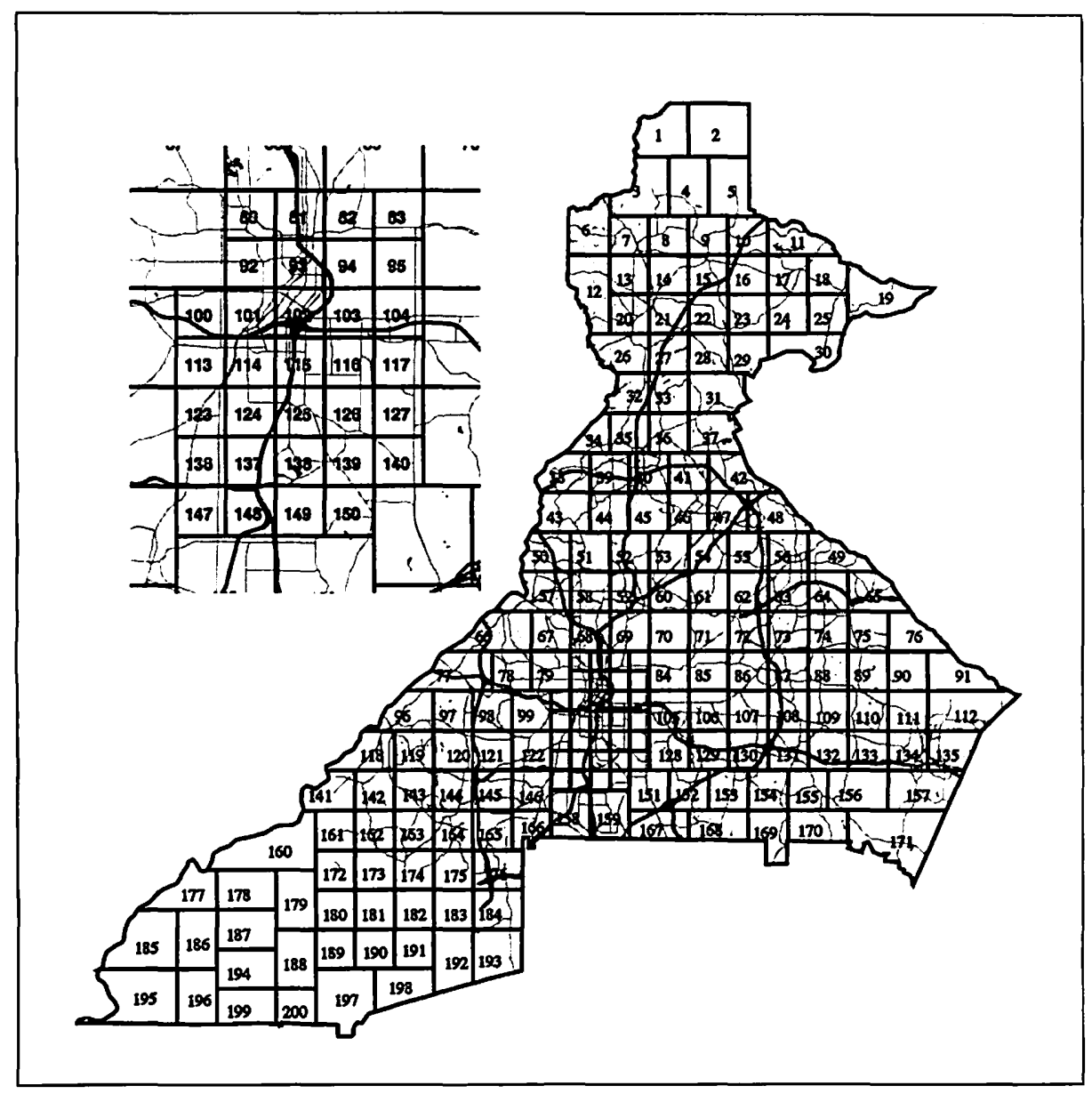

Figure 2. MARTA bus stop geocoding project: grid cell map.

the map so that the bus stop appears on the correct side of the intersection; or 3) move the bus stop in the GIS. The do-nothing alternative is not advisable for most applications. Customer service operators may direct patrons to the wrong side of the street. Work crews relying on GIS maps may not be able to find a bus stop if the map is wrong. Further, the automated tools that associate bus stops with route patterns will give incorrect associations if the bus stop is on the wrong side of the street. 
The second alternative may be preferable from an accuracy standpoint but edits to the underlying map may be difficult, especially if a commercially developed base map is used. This is the case with MARTA. While it is entirely possible for MARTA to modify the map, vendor updates to the map may not have these modifications. Thus, it is advisable to refer any changes to the underlying GIS map to the vendor. However, vendor-supplied updates may not be available in a timely manner. The third alternative involves moving the bus stop in the GIS. As long as the move is relatively small, most applications will not be affected. AVL is one exception. The annunciators and the automatic passenger counters may not relate to the correct bus stops. To account for this, it may be necessary to retain the true geographic coordinates as well as the map coordinates.

\section{A Bus Stop's Location Relative to Streets}

Coordinate locations are usually meaningless to most users of a bus stop inventory. These users rely on street descriptions to precisely locate a bus stop. The MARTA ITS uses one of four different ways to describe a bus stop's street location: address, intersection, midblock, or landmark.

For a bus stop located by address, the building number and on-street fields are populated. The intersection position field is set to "at" (at the street address) or "opposite" (across the street from the address). For bus stops at intersections, the on-street and at-street fields are populated and the intersection position field is set to nearside or farside. Midblock bus stops require an on-street, an at-street (for midblocks in the MARTA ITS, this is always the street ahead or down stream), and between-street (in the MARTA ITS, this is always the street behind or up stream). In using landmark descriptions, the location of the stop is given to the itinerary user as a landmark name. Thus, the patron is asked to board or alight a bus or train at a landmark (e.g., Lindberg Center Station) instead of an address (e.g., 2424 Piedmont Rd).

There is little debate among transit agencies that bus stops that are at the intersection (but not at a major landmark) should be described that way to cus- 
tomers. The question arises on how to describe midblock bus stops. Using the midblock technique described above could be problematic because there may be multiple midblock bus stops along a particular stretch of road. Using addresses solves this problem, but addresses are sometimes difficult to identify during a field survey. Further, address descriptions are usually less descriptive to a patron then a midblock description. For example, patrons usually find it more difficult to mentally visualize the location of the bus stop at "1040 Peachtree Street" versus the bus stop on "Peachtree Street" between "10th and 11th Streets."

\section{Physical Description of the Bus Stop}

The fields that describe the physical characteristics of the bus stop are self explanatory. One problem with these fields is that many of them are somewhat subjective. Thus, it is important that each of these fields has a set of rules to follow to minimize conflicting values between different field survey personnel. The most important of the physical description fields are those that give an indication of the accessibility of a bus stop. MARTA has several fields that relate to accessibility. Americans with Disabilities Act (ADA) compliance is one of these fields. This was found to be one of the most difficult fields to populate during the field data collection. A bus stop may have a shelter that is ADA compliant in terms of pad size, etc., but the bus stop may not be accessible because there may be little or no sidewalk leading to the stop or they may not be a nearby curb cut or handicap ramp to allow a person in a wheelchair to access the shelter.

\section{Surrounding Area}

Nearby landmarks are vital to the ATIS application. A patron usually will prefer to identify an origin or destination by a landmark name rather than an intersection or address. Thus, landmarks should be included with bus stops when possible. One problem that occurred in the creation of the MARTA bus stop inventory was that the field inventory was done simultaneously with the creation of a landmark database. In the MARTA ATIS application, the name of a landmark associated with a bus stop must exactly match a landmark name in the landmark database. This was often not the case because the bus stop field surveyors did not know what the exact landmark names would be. To avoid this 
problem, a transit agency should consider creating a landmark database prior to creating a bus stop database. Thus, a list of landmarks could be taken into the field by the bus stop surveyors to ensure that proper landmark names are used.

\section{Bus Stop Database Development}

There are several methods that could be used to geocode the location of bus stops. Surveying from known geodetic points will provide very accurate results but this method is very costly. Dead reckoning from nearby intersections is much less costly and can provide reasonable results as long as an accurate basemap is used to determined the bus stop's coordinates from the dead reckoning information. A third possibility is to use a differential GPS. A review of literature indicated that bus stops have never been inventoried using GPS prior to the development of the MARTA ITS. The successful use of GPS in similar applications such as the collection of traffic sign locations (Poling et al. 1993) and utilities delineation (Bricker and Kemmer 1995) made it evident that GPS would be viable for bus stop collection.

Because of the GPS's capability to provide instantaneous coordinate information, it was selected as the primary geocoding tool for building the MARTA bus stop inventory. It was anticipated that an alternative geocoding method would be needed in some instances because of limitations of GPS. Buildings, topography, and satellite positioning can adversely affect a GPS's ability to generate accurate coordinate information. In these instances, either dead reckoning from known points or "heads-up" digitizing on a street map displayed on a laptop computer could be used. GPS accuracy is also affected by the amount of time that the GPS is collecting coordinates at a single location. The best results are achieved by allowing the GPS to collect a minimum of 180 seconds of data. During this time, the field worker can type in associated attribute data.

For the MARTA ITS, the bus stop inventory development involved three broad tasks: 1) field survey, 2) office processing, and 3) field verification. Each of these tasks included several subtasks. Careful records were kept throughout the collection process to ensure that the final bus stop database was complete and accurate. 


\section{Field Survey}

The field survey was conducted using a notebook computer connected to a Trimble Pathfinder GPS receiver (Trimble 1991). This particular GPS receiver is capable of providing two-meter accuracy through post-process differential correction. Carrier phase surveying quality GPS receivers can provide sub-centimeter accuracy but the relative benefit of having this accuracy did not justify the additional cost of the receivers.

Specialized software was used in conjunction with the GPS to collect the bus stop data. Georesearch's Geolink product was used as the inventory software (Georesearch Inc. 1995). Geolink was chosen because it could be easily customized to collect bus stop attributes. The computer/software combination was connected to the Trimble GPS receiver and brought into the field to collect bus stop information. As data were collected by the GPS, the position of the bus stop was immediately shown on the computer display with a background map of streets serving as a position reference. The output from the GPS receiver was stored on the notebook's hard drive along with any related attribute information entered in by the surveyor. Each individual piece of data was automatically time-tagged and geo-referenced. Attribute information was entered through the customized Geolink user interface.

There are several benefits of collecting bus stop information in this manner. First, the position of the bus stop can be accurately recorded to within two meters of its actual real world coordinates (accuracy is dependent on satellite availability, obstructions, and other factors). Second, because attribute information is recorded directly into a digital format, errors caused by transferring handwritten notes into a digital format can be eliminated. Third, the user interface checks for errors as the data is entered (e.g., if an input value is out of range). Furthermore, the interface provides "pop-up" scroll lists for data fields that have a limited number of possible entries from which to choose.

\section{Office Processing}

Office processing involved differentially correcting the GPS coordinates, assigning a permanent stop ID, and uploading the bus stop data to a GIS for 
further processing. Without differential correction, bus stop positions can be off by more than 100 meters. Once in the GIS, the bus stop data were checked for completeness and quality. After all of the bus stops in a particular grid cell were collected, a hardcopy map was created for field verification purposes.

\section{Field Verification Procedures}

Field verification of the MARTA bus stop data was done by bringing a map graphic into the field with the associated bus stops displayed. An attribute table containing bus stop information accompanied the map graphic. Map graphics were created on a grid cell basis. This was found to be preferable to an individual route because it minimized redundant verification of road segments that had multiple routes. The purpose of the field verification was to ensure that bus stop data were as accurate as possible before being uploaded into the MARTA ITS database. Things that were looked for during the field verification were missing or misaligned bus stops, omissions in attribute fields, errors in attributes, and problems with the route alignment or the underlying street network on the hardcopy map. Corrections were made right on the hardcopy graphic and the attribute table. In some cases, it was necessary to resurvey the data using the GPS. After corrections were made, the verified bus stop information was uploaded into the MARTA ITS database.

\section{Association between Bus Stops and Route Patterns}

For the bus stop inventory data to be used in many of the ITS applications, associations between the bus stops and the route patterns must be defined. Although automated GIS tools can assist in the development of these associations, a significant manual effort is required to ensure that the associations are correct. The characteristics of bus stops complicating this task include station bus bays, near-side stops that cannot be used by buses that need to be in the left lane to make a left turn, and stops appearing on the wrong side of the road on the GIS map. More significantly, the quantity of route pattern variations contributes to the size of this task. Distinct patterns exist for route alternates, including areas only served by certain trips, abbreviated or combined weekend service, variations in AM and PM layovers, and short trips used in combination with dead- 
heads to and from garages. Additionally, the patterns and associations must be distinguished by direction (e.g., inbound vs. outbound). In the MARTA database, 143 routes consist of 770 distinct patterns, and more than 30,000 pattern associations exist for the approximately 10,000 defined bus and rail stops. These associations between bus stops and route patterns are stored in the stop-on-pattern table in the database (see Figure 1).

\section{Maintaining the Bus Stop Database}

Maintaining the bus stop database is as important as the collection and verification process for a number of reasons. First, changes in routes to accommodate new landuses and changes in the infrastructure will require moving or removing existing stops and adding new ones. Second, physical entities that make up a bus stop (i.e., the stop indicator or shelter) will require periodic maintenance. Third, because of their proximity to streets, bus stops are prone to damage from passing vehicles. In some cases, a stop that is damaged may be moved or its physical characteristics may be altered in an effort to minimize the potential for future damage from adjacent traffic (Federal Transit Administration 1996).

An out-of-date or poorly-maintained bus stop database may lead to erroneous information being given to a patron. Further, an accurate maintenance history will make it easier to predict and program future bus stop maintenance needs. Furthermore, the accuracy of the bus stop information will undoubtedly affect the various applications that require up-to-date bus stop information. One example is if the system has a bus stop annunciator capability. The announcement of a bus stop that no longer exists on a particular route would be undesirable for obvious reasons.

The maintenance of bus stop information in the MARTA ITS occurs within a GIS user interface. Figure 3 shows a sample maintenance screen. The user can select a bus stop for editing either by picking it from the GIS map display (Figure 4 ) or by selecting it from a scroll list of stop IDs. Bus stops are indicated by triangles in Figure 4. This figure also shows landmarks, bus routes, and a MARTA rail station (indicated with a round symbol). If desired, map features can be hidden to reduce clutter. 


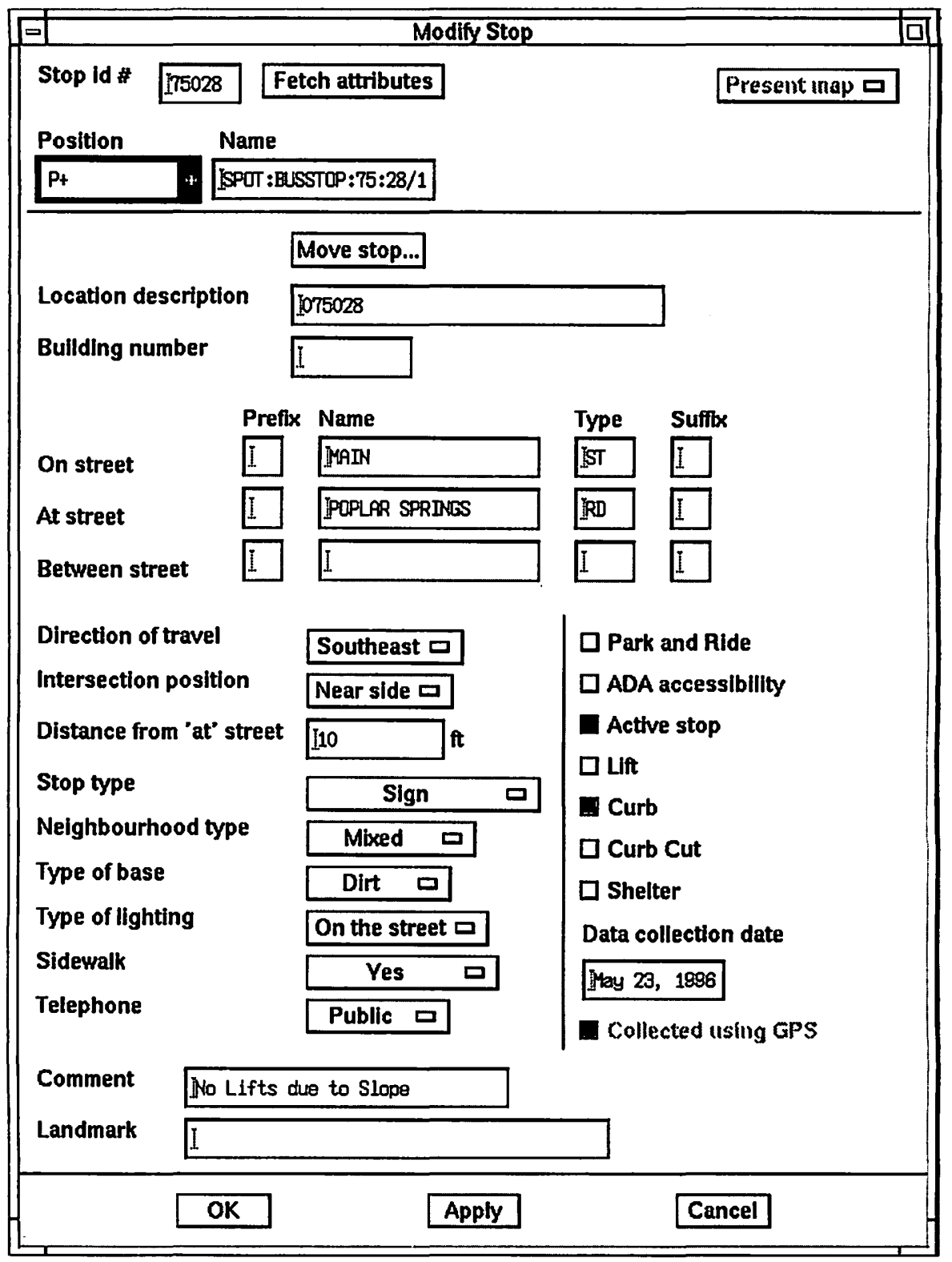

Figure 3. Bus stop maintenance screen. 


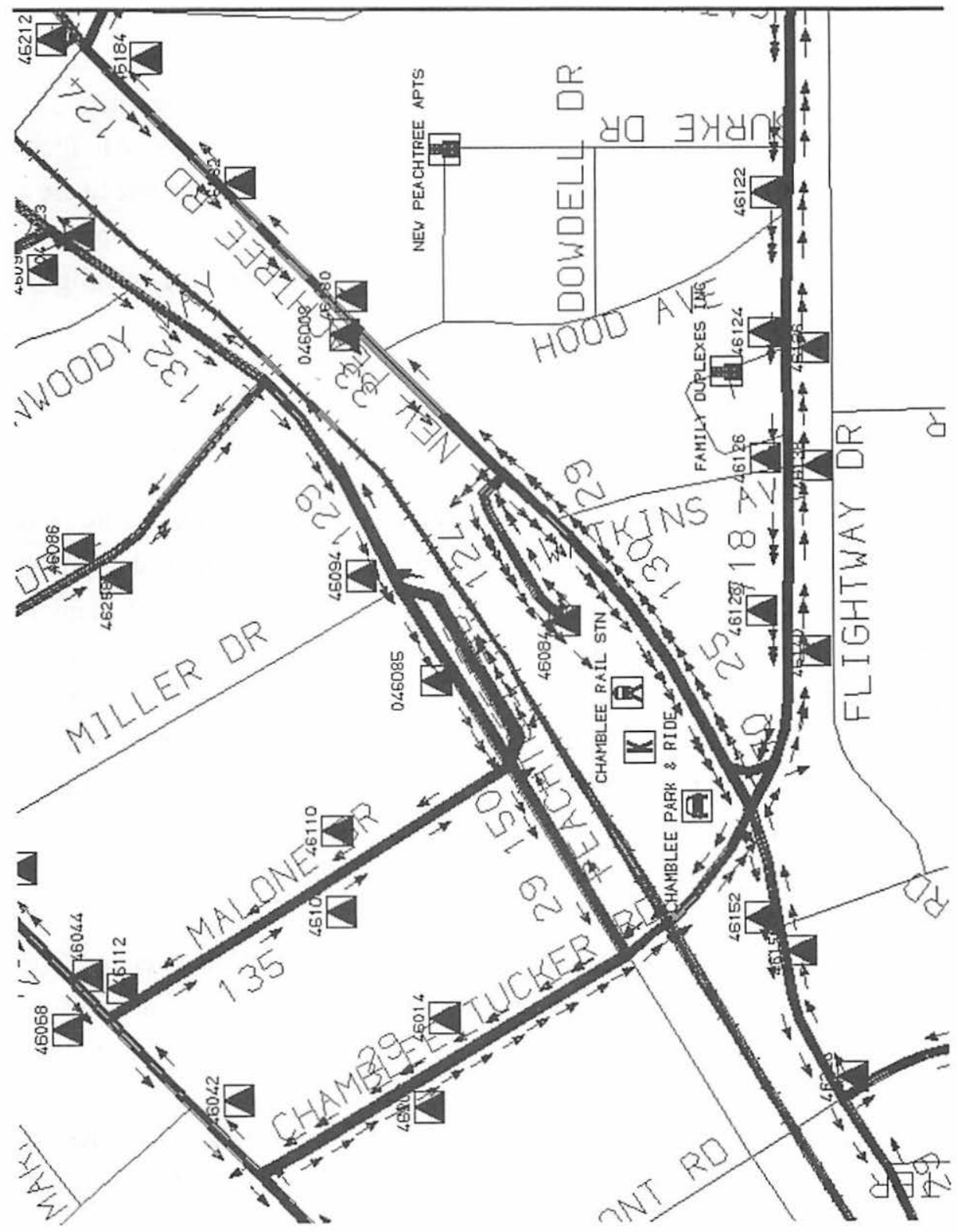

Figure 4. GIS map display. 


\section{Bus Stop Work Orders}

Figure 5 illustrates the bus stop work order form that is used by MARTA. The information on the left of the figures are attributes of the bus stop. The section to the right refers to the work to be performed as well as a spot to illustrate a bus stop. When a bus stop is being moved, it is usually preferable to use a GPS system to inventory the coordinates of the new location. This is especially important from an AVL standpoint because the AVL relies on the actual geographic coordinates of the bus stop.

\section{Conclusion}

There is a trend in the transportation industry to take advantage of evolving technologies that have had a significant impact on ITS such as GPS, GIS, and more powerful computer capabilities. MARTA has jumped on this bandwagon and, because of its recent efforts, has become a leader in ITS applied to public transportation. The main purpose of MARTA's ITS is to provide important information in a timely fashion. Whether it be trip itineraries to customer service operators, real-time bus locations to radio room operators, or bus stop announcements to MARTA patrons-the MARTA ITS is already enhancing operations on a number of fronts. Transit planning will also benefit from this system because passenger counting can be done in an automated fashion. Further, the recorded boardings and alightings can be associated with bus stops because of the AVL capability on selected bus routes.

An integral component to the MARTA ITS is the bus stop inventory. The lessons learned from MARTA's experience in creating and maintaining this inventory should be valuable to other transit agencies that are planning or are in the process of implementing an APTS. The Utah Transit Authority (UTA) has recently built a bus stop inventory that made use of some of the techniques described here. UTA is in the process of implementing an APTS that should be in place in time for the 2002 Olympics. 
TO:

DATE:

ROUTE:

FROM:

DATE REC:

I.D.H:

APPROVED:

DATE COMP:

ITS:

Answer Appropriate Block

Inbound $\square$ Outbound

On Street - plus type (e.g. Ave. Dr., etc.

At Street - plus type (c.g. Ave. Dr., etc.)

At Street near side, far side

Distance of Stop from the At Street feet (if less than 200' from corner)

Direction of Travel - N,S,E,W,NE,SE,NW,SW

Exact Corner - NE, SE, NW, SW

Mid Block -only when a bus stop is greater than $200^{\prime}$ from an intersection. AT $\square$ Opposite Address: (Block \# (over 200' from comer)

ADA Accessibility, $\mathrm{Yes}(\mathrm{Y}), \mathrm{No}(\mathrm{N})$

Sidewalk - Yes(Y), No(N), Yes but poor

Condition(YP). Yes but Short(YS).

Lift - Can lift be used? Yes $(Y)$ No $(N)$, No beciuse of incline (NI)No because of Shoulder Drop-off (NS).

Carb denotes presence of curb at bus stop Yes( $(Y)$, No(N), Yes but not lift accessible (YN)

Curb Cut - wheelchair accessible from sidewalk to street. Yes (Y), No (N), no sidewalk or curb (NA)

Telephone - None(N), Public(P), Nearby business(B)

Present Bus stop type - Sign (SGN) Post (POS), Strap (STR), MARTA Shelter (SHM), Advertisement Shelter (SHA), Pedestal Stop (PS)

Neighborhood Type - Commercial (Com) School (Sch) Industrial (IND), Mix (MIX)

Base - Type of base Concrete (Conc) or Dirt (Dirt).

Lighting - On street (S) Dedicated (D) or Poor (P)

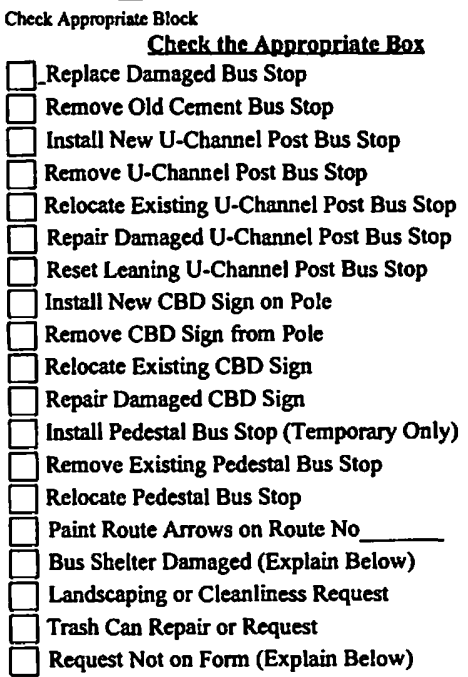

Check Appropriate Block

Check the Anpronriate Box

]_Replace Damaged Bus Stop

Remove Old Cement Bus Stop

Install New U-Channel Post Bus Stop

Remove U-Channel Post Bus Stop

Relocate Existing U-Channel Post Bus Stop

Repair Danaged U-Channel Post Bus Stop

$\square$ Reset Leaning U-Channel Post Bus Stop

Install New CBD Sign on Pole

Remove CBD Sign from Pole

$\square$ Relocate Existing CBD Sign

$\square$ Repair Damaged CBD Sign

$\square$ Install Pedestal Bus Stop (Temporary Only)

Remove Existing Pedestal Bus Stop

Relocate Pedestal Bus Stop

Paint Route Arrows on Route No

$\square$ Bus Shelter Damaged (Explain Below)

Landscaping or Cleanliness Request

Trash Can Repair or Request

Request Not on Form (Explain Below)

Pick the Appropriate street map, name the ON street, name the AT street, and spot the stop at the appropriate location on the map.

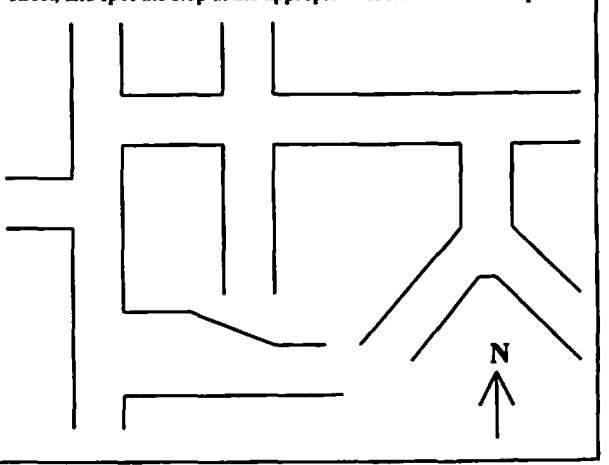

Date called

Utillties Protection Network 1-800-282-741 I Utility Location \#

A.M. P.M.

Date and Time Approved to Dig: From

A.M. P.M. To

Special Instructions:

WORK PERFORMED BY

22-8470 (Revised 1//97)

TIME:

A.M. P.M.

Figure 5. Bus stop work order form. 


\section{References}

Bricker, R.T., and C. Kemmer. 1995. Up the Pole, Down the Lane: GPS on the Utilities Circuit, in GPS World, January, Advancestar Communications, Duluth, Minnesota: $16-24$.

Casey, R.F., L.N. Labell, R. Holmstrom, J.A. LoVecchio, C.L. Schweiger, and T. Sheehan. 1996. Advanced Public Transportation Systems: The State of the Art Update '96. Report FTA-MA-26-7007-96-1. Federal Transit Administration, Washington, D.C.. Federal Transit Administration. 1996. Guidelines for the Location and Design of Bus Stops, TCRP Report 19, Transit Cooperative Research Program, Washington, D.C. Georesearch Inc. 1995. Geolink GPS/GIS Data Collection Software Manuals, Billings, Montana.

Poling, A., J. Lee, P. Gregerson, and P. Handly. 1993. Comparison of Two Sign Inventory Data Collection Techniques for Geographic Information Systems. In Transportation Research Record 1429, TRB, National Research Council, Washington, D.C.: $36-39$.

Trimble Navigation Ltd. 1995. Pathfinder Basic Plus User's Manual, Sunnyvale, CA.

\section{About the Authors}

Wayne Sarasua is an Assistant Professor in the School of Civil and Environmental Engineering at Georgia Tech. His research interests focus on the application of spatial data analysis technologies in transportation.

Robert Awuah-Baffour is an Assistant Professor in the Civil Engineering Department at Bradley University. He recently finished his doctorate in the School of Civil and Environmental Engineering at Georgia Tech. His doctoral thesis explored the use of a specialized attitude GPS unit to collect roadway grade and cross slope information simultaneously.

MARK Fawley is a Project Manager for TRW. His expertise is in large software system development and integration and relational database design.

Carlton Byars is in charge of bus stop maintenance at MARTA. He is responsible for the upkeep of all GIS bus-stop-related databases including landmarks, timepoints, and announcement points.

JefFery OrTon is the GIS Coordinator with the Utah Transit Authority. He is in charge of maintaining the databases that support UTA's GIS. 


\title{
Markets, Politics, and Environmental Policy Issues for Public Transit
}

\author{
David A. Hensher \\ The University of Sydney \\ Michael E. Beesley \\ London Business School
}

\begin{abstract}
Economic deregulation of local bus services remains controversial in terms of the claimed gains and losses relative to competitive regulation in the form of competitive tendering or negotiated protected monopoly. The uncertainty over demonstrable net benefits has delayed, if not eliminated, any prospects for unleashing market forces in London where competitive tendering is claimed by its supporters to be at least as attractive as economic deregulation in terms of quantity and quality of service. While the literature has focused predominantly on the economic and social impacts of market reforms, some of the changes have brought about environmental gains and losses. These rarely have been documented, being overshadowed by the initial objectives motivating economic reform. One particular feature of economic deregulation in the United Kingdom (and to a lesser extent in Australia and New Zealand) has been the noticeable increase in minibus services. The impact that economic deregulation has on entrepreneurial innovation has been neglected in the public transport literature, yet it is a centerpiece of competitive strategy. We use the experience with minibuses in Britain to show how markets create environmentally compatible incentives. Environ-
\end{abstract}


mental gains attributable to market reform counter in part the negative evidence that minibuses in Britain have "failed" to stimulate an aggregate increase in ridership. Without knowing the counterfactuals, one might speculate that the outcome would have been even worse without the introduction of the minibus.

\section{Introduction}

The United Kingdom experience of bus deregulation and privatization has been taken as perhaps the most important example of the role of using market forces to meet government objectives in transport. Economic deregulation in 1985 was designed to remove the binding constraint on competitive bus entry, leaving the latent barriers to entry to be revealed. The academic debate has been extensive (see Mackie and Preston 1996; Mackie et al. 1995; Beesley and Glaister 1985; Gwilliam et al. 1985). It has tended to be polarized as a confrontation of two views: either to let market forces decide what should be provided in terms of bus outputs and qualities, or retain government definitions of what should be produced, while using market processes to provide the means via competitive tendering. It is a common belief that either leads to substantial cost savings; the disagreement is about the resulting level and quality of outputs.

One important argument in the political debate that has assumed much greater practical importance in the last 10 years-namely, environmental objectiveshas been neglected in the exchanges on bus policy. Specifically, it is unclear what influence the changes have had on emissions, which are seen of great environmental significance. We offer a preliminary view, concentrating in particular on the impact of the minibus "revolution" on greenhouse gas emissions and using the counterfactual of a similar aggregate bus sector output.

The impact that economic deregulation has on entrepreneurial innovation has been neglected in the public transport literature, yet it is a centerpiece of competitive strategy. Seeking out entrepreneurial activity is an attractive way of shifting political agendas, at least in the countries with which we are most familiar, the U.K. and Australia; yet it has not been fully exploited by the privatization process, which emphasizes almost exclusively the reduction in the burden of government debt. 
A great attraction of the outcome of minibus provision is that it is politically'plausible, since the means employed to realize policy objectives are themselves credible-by reducing subsidy and improving customer service. Such innovation consistent with incentives, driven largely by market conditions, are fundamental to long-run profit and, hence, have appeal to entrepreneurial bus operators.

We use the experience with minibuses in Britain to show how markets create environmentally compatible incentives. Environmental gains attributable to market reform counter, in part, the negative evidence that minibuses in Britain have "failed" to stimulate an aggregate increase in ridership. Without knowing the true counterfactuals, one might speculate that the outcome would have been even worse without the introduction of the minibus.

\section{Market Forces as Natural Generators of Innovative Activity}

The view that government must intervene in an overt way for negative environmental impacts to be minimized is as alive today as it was 30 years ago when, in July 1966, the U.K. Minister of Transport presented to Parliament the white paper titled "Transport Policy" (HMSO 1966). The first paragraph stated that:

... The rapid development and mass production of the motor vehicle over the past 20 years has brought immense benefits to millions of people: increased mobility, a fuller social life, family enjoyment, new experiences. . . . But at the same time it has brought severe discomforts: congestion in the streets of our towns; the misery of the journey to work for commuters; noise, fumes and danger as the setting of our lives; a rising trend of casualties on our roads and a threat to our environment in both town and countryside which if it continues unchecked, will ensure that the pleasure and benefit for which we use the car will increasingly elude us. The aim of a rational transport policy must be to solve this paradox. 
The policy statement went on to state:

... Our towns and cities will never be able to cope with their traffic, or the transport needs of millions of people, without strengthening, improving and expanding their public transport services. ... Clearly these services must adapt themselves to new technological developments, but to get more people . . . moved with less road space is vital to the solution of our transport problems. ... New thinking is required, not only about types and combinations of public transport, but also about how they should be financed. To attempt to solve these problems in exclusively commercial terms is to bring the Victorian mentality to the solution of modern needs.

An implication of this white paper is that government, through planning processes, has a greater chance of providing the necessary incentives to secure improved public transport as an antidote to the automobile, in contrast to the market. This duly underpinned the government's attitude toward public transport, and its willingness to subsidize to do so, whatever party was in power, up to the early 1980s. The position promoted in this paper is that the information required by government to plan can only be generated efficiently if markets are allowed to function. Deregulation in Britain since 1985 provides the best empirical setting for evaluating the innovations that have been initiated by the power of the market (even if the benefits have spilled over into all supply regimes) (GomezIbañez and Meyer 1997).

While it is true that, to date, demonstration of gains to bus business from environmental innovativeness, in particular, is not widespread, there is very encouraging evidence emerging (see below) that market forces create opportunities for innovative activity, which is not only supportive of profits but has desirable environmental outcomes. Through the example of minibuses-a product of market driven incentives - we show that government, prior to the 1985 Act, may have restricted the opportunities to improve public transport in contrast to acting as if they were embellishing opportunities for better public transport. 
The question not addressed in the literature on bus provision is the extent to which innovative opportunities are greater under regimes that lessen the power of the regulator in delivery of services. It may be the case that the empirical evidence, as limited as it is, is misleading because of the failure of incentive structures to deliver the gains that are inherent in a less constrained market. What we need to understand are the circumstances under which incentives can evolve and be effective. One problem with the bus industry may be that the lack of experience in managing change and/or the reticence in being innovative, given a history of suppression of innovation, is hampering the speed of taking up opportunities waiting for action. Generational inheritance, for example, which often lacks an understanding of the need to sustain wealth and survival, leads to a reduction in entrepreneurial activity and, hence, a decline in any potential innovation. Why has the minibus and hail-n-ride only been introduced in the era of deregulation/competitive regulation and potential competition in the U.K., New Zealand, and Australia? As Porter and van der Linde (1995) comment in the context of environmental innovativeness spurred by competition:

We are currently in a transitional phase of industrial history where companies are still inexperienced in dealing creatively with environmental issues.

The literature that looks at the broader set of potential benefits concentrates on direct benefits to users (e.g., Nash 1988; Ellis et al. 1996; Evans 1990; Mackie et al. 1995) showing variability in gains and losses to users. A strong case has also been mounted against supply opportunities that do not preserve the regulator's control on demand-coordinating mechanisms such as timetables and ticketing (see also Tyson 1995). Indeed, Evans' (1990) argument for natural monopoly in the supply of local schedule route services is predicated entirely on the role of economies of network interdependencies so as to minimize uncertainty and waiting time, etc., in transfers. 


\section{The Minibus and the Environment}

Urban passenger transport demand is multi-dimensional. It encompasses the location of activities, the alternative travel opportunities available, and the availability of types of motorized and non-motorized transport. A potential user of the transport system faces choice opportunities with varying degrees of availability. In the long run, individuals have increasing opportunities to review all key transport-related choices-where to live, where to work, the number and types of automobiles in the household, the choice of means of transport and time of departure for the journey to work, and even negotiation of the temporal and spatial nature of working hours (i.e., flextime, a compressed work week and telecommuting). In the short run, some of these choices are not available and, hence, condition the choices that can be evaluated and changed.

Using a model system of the household sector developed for Perth, West Australia (Hensher 1996), we have evaluated their impact over the period 19932003. The model system is an integrated land-use and transport system incorporating linked models for household location decisions, vehicle choice decisions and travel decisions (timing, mode choice, workplace location choice).

The behavioral models in the simulator are presented in sub-modules representing the four natural divisions of:

(1) commuter choice: spatial and temporal choice of working hours, departure time choice, mode choice, and workplace location choice;

(2) automobile choice: vehicle type choice and household fleet size choice;

(3) residential choice: location and dwelling type choice; and

(4) automobile use: total annual vehicle and household kilometers and the spatial composition of kilometers.

The decision blocks for location decisions, vehicle decisions, and travel decisions and their major linkages are summarized in Figure 1. Each of the blocks has a set of internal linkages; the blocks are themselves linked by a set of external linkages. The inclusive value (IV) indices provide behavioral linkages between discrete choices that are globally consistent with utility maximization; the selectivity correction (SC) indices provide equivalent linkages between a dis- 


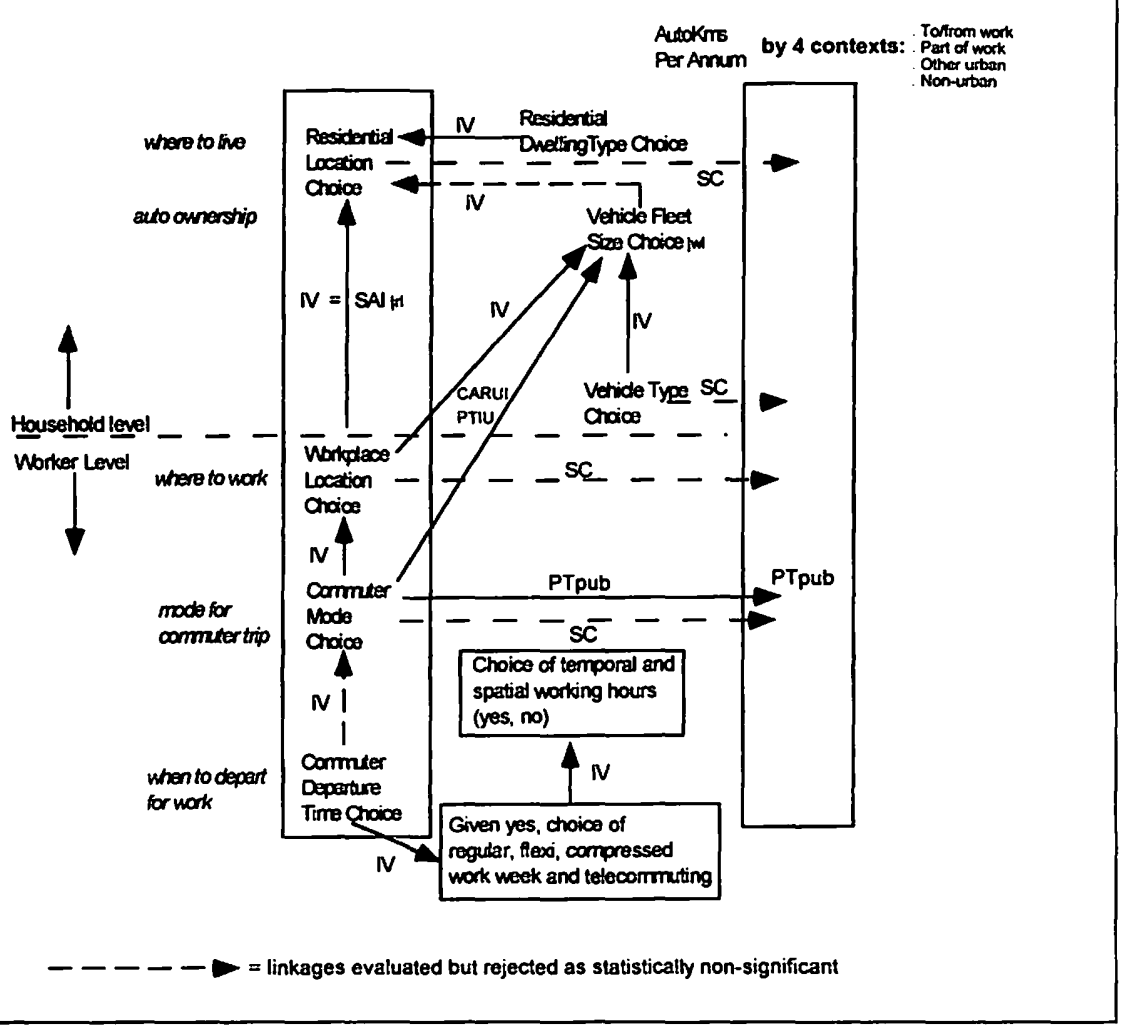

Figure 1. The Linked Model System (IV = inclusive value index, SC = selectivity correction) (Hensher 1996).

crete choice (e.g., vehicle type) and a continuous choice (e.g., vehicle kilometers). Three instruments (land rents, used vehicle prices, and commuting travel times) are used to equilibrate within three of the decision blocks, with the option to bypass vehicle market equilibration. The non-commuting car use decision block does not have a market clearing facility in the current specification.

There is an assumed decision hierarchy in which residential location is the uppermost decision of a household, and, as we move down the decision tree, we condition each of the worker-related choices on the higher order decisions. The choice of workplace location for each worker in a household is conditional on 
the household's choice of residential location. Likewise, the choice of commuter mode is conditional on the choice of residential and workplace location. The presence of more than one worker in a household is allowed for by having a separate choice for each worker, together with additional exogenous variables to account for the influence of the number of workers on each worker's choice of mode, workplace, and household residential location. The modal opportunities include the set of available alternatives and possible future investments in "new" modes in specific spatial contexts, such as light rail and bus priority systems. Stated choice experiments are combined with revealed preference data in the estimation of the departure time choice and commuter mode choice models. Full details of the simulator are presented in Hensher (1996) and Hensher et al. (1995).

To understand how we identify the impact of a policy instrument, consider an increase in service frequency. The imposition of this improved service via its impact on the generalized cost of using buses has an immediate and direct influence on (1) the use of each competing means of transport for particular trips such as the commuter trip, (2) a possible change in the timing of the particular journey, which creates a further change in the generalized costs associated with traffic congestion, and, hence, (3) a possible change in the overall and non-commuting use of each automobile available to a household. It may directly affect the household's choice of types of automobiles. The indirect impacts may, in the longer term, include a change in residential location via the change in modal and spatial accessibility to work opportunities, and a change in the number of vehicles in a household (given the reduced demand for auto use). Changes in residential location may further affect the total use of each automobile, as well as the mix of urban (commuting and non-commuting) and non-urban kilometers. The adjustment in commuter travel may also affect non-commuting car use.

The adjustments in vehicle, travel, and location choices at the household level translate at the aggregate level into a new set of equilibrium levels for traffic congestion (broadly measured by the ratio of travel time to distance traveled), residential densities, total kilometers of travel by automobiles and various forms of public transport, fuel consumed, and greenhouse gas emissions. Table 1 
summarizes the results of emission changes (and other interesting statistics) in bus frequency with the introduction of minibuses in which we replace all large buses with minibuses. This substitutes better fuel consumption (in liters per $100 \mathrm{kms}$ ) and

\begin{tabular}{|c|c|c|c|}
\hline \multicolumn{4}{|c|}{$\begin{array}{c}\text { Table } 1 \\
\text { The Impact of Minibus Substitution in } \\
\text { Perth, West Australia, 1993-2003 }\end{array}$} \\
\hline \multirow{2}{*}{$\begin{array}{l}\text { Outputs } \\
\text { Change in: }\end{array}$} & \multicolumn{3}{|c|}{$\begin{array}{c}\text { Minibus Substitution } \\
\text { Bus Frequency }\end{array}$} \\
\hline & $\begin{array}{r}10 \% \\
\text { increase }\end{array}$ & $\begin{array}{r}20 \% \\
\text { increase }\end{array}$ & $\begin{array}{r}10 \% \\
\text { decrease }\end{array}$ \\
\hline $\mathrm{CO}_{2}$ (mean \% pa) & -0.16 & -0.34 & 0.18 \\
\hline End user cost (\$mpa) & -3.0 & -4.8 & 3.1 \\
\hline Car vkm (mean\%pa) & -0.23 & -0.51 & 0.20 \\
\hline Auto energy (mean\%pa) & -0.24 & -0.56 & 0.22 \\
\hline Govt auto rev (\%pa) & -0.21 & -0.47 & 0.20 \\
\hline Car commuting share (\%) & -1.0 & -1.8 & 0.85 \\
\hline
\end{tabular}

changes the frequency of service. All changes commence in 1996. The cost items are calculated in constant dollars (\$93), but are converted into present values at a real discount rate of 8 percent per annum over 10 years for all dollar-based items. Minibuses average 15-20 liters per $100 \mathrm{kms}$ in U.K. in the late $1980 \mathrm{~s}$ (White 1988), and 16-18 liters/100km in Sydney, Australia in 1997 (Westbus Nepean Nippers), compared to a large bus of $38-42$ liters per $100 \mathrm{kms}$.

The change in $\mathrm{CO}_{2}$ with increased frequency is the net effect of:

(1) changes in vehicle fuel efficiency (liters $/ 100 \mathrm{~km}$ ) due to switching large buses for small buses,

(2) changes in aggregate vehicle kilometers provided by buses with increased frequency,

(3) modal switching from car to the improved bus service, and

(4) possible changes in household automobile fleet size and composition and the location of work and residential activity. 
Changes in bus kilometers and car kilometers are highly correlated with changes in emissions of $\mathrm{CO}_{2}$.

Although small as a percentage change, minibuses accompanied by increased service frequency decrease carbon dioxide emissions. The majority of the change in $\mathrm{CO}_{2}$ is attributable to items (1), (2), and (3) above. In particular, gains in fuel efficiency and increased bus modal share reduce $\mathrm{CO}_{2}$ by 1.7 percent, while increases in bus vehicle kilometers increases $\mathrm{CO}_{2}$ by 1.55 percent. The impact of relocation of work and residential activity was negligible in the current application (net impact of -0.01 percent in $\mathrm{CO}_{2}$ ), but recognition of the potential for relocation of activities is important in assessing the net impact of policy instruments.

The increase in service frequency (often linked to the introduction of minibuses) has a noticeable impact on total end user costs (money and time costs), reducing them by up to $\$ 4.8 \mathrm{~m}$ per annum for all travel for a 20 percent improvement in frequency compared to headways offered by large buses under current timetables. The impact on energy consumed, automobile kilometers, and revenue to government from automobile use is small, less than 1 percent.

The simulations undertaken are an improvement over the very aggregate partial analysis of the impact of minibuses undertaken by Banister and Banister (1995), which concludes that a minibus is 27 percent less fuel efficient on a per passenger basis than a large bus, and the study by White and Turner, which estimates, on balance, due to a partial shift to minibuses in Britain, less than 2 percent saving in fuel costs per bus kilometer (White and Turner 1990). Environmental gains attributable to market reform counter, in part, the negative evidence that minibuses in Britain have "failed" to stimulate an aggregate increase in ridership. Without knowing the counterfactuals, one might speculate that the outcome would have been even worse without the introduction of the minibus.

\section{Fuel Excise and the Environment}

Another policy instrument with positive environmental outcomes is a fuel excise applied to all modes. The impact of reduced greenhouse gas emission is 
substantial, as might be expected (Table 2). The net changes in $\mathrm{CO}_{2}$ associated with a fuel excise tax are predominantly due to changes in vehicle use (and the mix of vehicle types in the car park), with very little associated with substitution between cars and large buses under existing timetables. Clearly, a general policy instrument applied to all modes, especially the automobile, will have a

\begin{tabular}{|lcc|}
\hline \multicolumn{3}{|c|}{ Table 2} \\
The Impact of Fuel Excise in \\
Perth, West Australia, & $1993-2003$ \\
\hline & \multicolumn{3}{c|}{ Fuel Excise on } \\
Ontputs & on Cars and Buses \\
\hline Change in: & $60 \mathrm{c} / 1$ & $80 \mathrm{c} / 1$ \\
CO2 (mean \% pa) & -9.0 & -17.4 \\
End user cost (\$mpa) & 68.9 & 125 \\
Car vkm (mean\%pa) & -9.07 & -17.4 \\
Auto energy (mean\%pa) & -8.80 & -17.3 \\
Govt auto rev (\%pa) & 18.3 & 32.4 \\
Car commuting share (\%) & -0.61 & -1.23 \\
\hline
\end{tabular}
greater impact on the environment than a policy applied to a public transport mode; and thus, in evaluating the change in innovation attributed to the minibus, we will never be able to establish a level of environmental benefit that can match any level achievable with even a relatively modest fuel excise. Importantly however the real difference between the two policy instruments is that people are revealea to prefer minibuses and dislike taxes.

As an environmentally attractive policy instrument, sizeable fuel excise increases achieve more impact than does adjustments in levels of frequency of buses. Although improvements in vehicle fuel efficiency reduce total end user cost substantially, the impact on energy and $\mathrm{CO}_{2}$ is significantly less than a fuel excise. However, in terms of the political cost of policy changes, the payoff to minibuses is highly likely to be superior; changes in tax levels associated with minibus deregulation are negligible. 


\section{Deregulation and Innovation in Bus Operations: Extracting Some Counterfactuals}

To throw some light on the issue of innovations accompanying deregulation, to complement the simulation undertaken in the previous section, we undertook a survey of a number of route services operators in New Zealand and the United Kingdom who are operating under a deregulated regime. Information was also sought from some Sydney (Australia) operators who provide services under an area contract subject to minimum service levels and maximum fares (see Brewer and Hensher 1997). The responses are reproduced in Appendix A. Counterfactual knowledge of the situation under regulation is not available. All that we have to rely on is the evidence offered by operators in the deregulated market. The findings suggest that there have been noticeable beneficial changes in vehicle kilometers delivered and patronage as well as innovative examples, especially under economic deregulation. Innovations attributed to the deregulated environment are the introduction of minibuses, increased service frequency, marketing by segments, more fuel efficient buses, and more flexible route design.

What we find not only supports the position that relaxing constraints on the market's operations has a direct innovative effect on operators now in deregulated markets, but it appears to create spillover effects into restricted markets who see the benefits of such innovative activity. A good example is minibuses increasingly used on competitively-tendered routes as well as on operations, where the incumbent remains protected by anti-competitive area franchises, as is the case in the main throughout Australia.

Concern for the environment means a shift toward a larger number of modal opportunities for transport users as well as a recognition that environmental benefits may arise from many behavioral responses such as the endogenous set of location, vehicle, and travel choices operating in the travel simulator applied to Perth. This leads to less reliance on mode outputs as proxies for the greater good and increasing input or reliance on market driven means. This is consistent with a shift towards more indirect instruments of policy, such as indirect taxes and 
competitive rules, rather than protection or enhancement of particular transport modes.

Furthermore, allowing markets to generate fresh opportunities for profit making is a means to encourage relevant charitable activities. Successful business people are able to pursue their own enthusiasms because of that profit. Indeed, the outstanding innovations have arisen in this way. Perhaps most notable in the U.K. were the pioneering efforts in housing and planning by the chocolate and soap entrepreneurs, Cadbury, Rowntree, and Lever. Nowadays, environmental innovation should be no exception, and successful transport operators are seen as a fertile ground. In the research for this paper, for example, we found minibus operators to be unaware of the possible connection between their operation and pollution reduction. Once it is pointed out via the indirect effects we have described, interest is stimulated by the perception that here is another reason for minibus operations to be preferred by policymakers and is a case of promoting the public interest while making a profit. It is then quite conceivable that their interest will broaden into trade-offs that create more benefits even where this involves some increases in their outgoings-for example, on an excise tax imposed on all vehicles of a given engine capacity.

\section{Concluding Thoughts}

If it can be shown that there are political credits from innovations in the bus sector that are supportive of broad-based environmental objectives of government, then this gets political attention. It also raises the limitation of the promotion of better cost-benefit analysis in a political sense-at the margin, CBA enhancements cannot be traded since other politically-competing sectors fail dismally in producing such sophistication in technique to evaluate projects.

The empirical evidence that economic deregulation in the U.K. has produced sizeable increases in vehicle kilometers but no noticeable increase in passenger kilometers might, in a partial equilibrium setting, lead to the conclusion that the minibus has contributed to the aggregate reduction in passenger kilometers. What is missing in this inference is the counterfactual that may show an 
even worse diminution in passenger kilometers in the absence of the minibus "revolution." What we can suggest, however, is that the minibus has brought with it, on our evidence, small but noticeable environmental benefits (which may be even greater with the counterfactuals as the base).

If the unchanged quantity of patronage is now traveling on more environmentally-friendly bus systems in contrast to the pre-deregulated era, then the systemwide environmental benefits are positive. In particular, less greenhouse gas emissions are being generated in the delivery of an economic deregulated service. The example for greenhouse gas emissions should be extended to include other environmental impacts such as air quality, noise, and safety.

\section{References}

Banister, D., and C. Banister. 1995. Energy Consumption in Transport in Great Britain: Macro Leve Estimates, Transportation Research, 29A (1): 21-32.

Beesley, M.E., and S. Glaister. 1985. Deregulating the Bus Industry in Britain--(C) A Response, Transport Reviews, 5: 105-132.

Berechman, J. 1993 Public Transit Economics and Deregulation Policy, North Holland, Amsterdam.

Brewer, A., and D. A. Hensher. 1997. Operating a Bus and Coach Business: Insights and Practice, Sydney: Allen and Unwin.

Brindle, R. E. 1992. Transport and Land Use: A "Neo-Modern" Approach, Proceedings 16th Australian road Research Board Conference, Part 6: 111-136.

Ellis, C. J., and E. C. D. Silva. 1996. British Bus Deregulation, Preemption and Demand Coordination, Department of Economics, Eugene: University of Oregon (mimeo).

Evans. A. 1990. Competition and the Structure of Local Bus Markets, Journal of TransportEconomics and Policy, XXXIV (3), September: 255-282.

Gastaldi, M., J. P. Pradayrol, E. Quinet, and M. Rega. 1996. Valuation of Environmental Externalities: From Theory to Decision-Making, Transportation Planning and Technology 19: 207-219.

Gomez-Ibañez, J. A., and J. R. Meyer. 1997. Alternatives for Urban Bus Services: An International Perspective on the British Reform, Transport Reviews, 17 (1): 17-30. 
Goodwin, P. B., S. Hallett, F. Kenny, and G. Stokes. 1991. Transport: The New Realism, report to Rees Jeffrey Road Fund, Transport Studies Unit, University of Oxford.

Gwilliam, K. M., and D. M. Van De Velde. 1990. The Potential for Regulatory Change in European Bus Markets, Journal of Transport Economics and Policy, XXIV (3), September: 333-350.

Gwilliam, K. M., C. A. Nash, and P. J. Mackie. 1985. Deregulating the Bus Industry in Britain-- (B) The Case Against, Transport Reviews 5: 105-132.

Hensher, D. A. 1994. Transport Planning, Markets and Government: Challenges for the Future, International Journal of Transport Economics XXI (2): 147-156.

Hensher, D.A. 1996. An Integrated Approach to Modelling the Impact on Urban Travel Behaviour of Strategies to Reduce Enhanced Greenhouse Gas Emissions, World Transport Research, Proceedings of the 7th World Conference on Transport Research, edited by Hensher, D.A., J. King, and T. Oum, Oxford: Pergamon Press, Vol 1: 271-286.

Hensher, D. A., F. W. Milthrope, and M. Lowe. 1995. Greenhouse Gas Emissions and the Demand for Urban Passenger Transport: Final Report: Summary of Approach and Selective Results from Application of the ITS/BTCE Simulator; Report 8, Institute of Transport Studies, The University of Sydney, November.

HMSO. 1966. Transport Policy, Cmnd. 3057, London: HMSO.

Kennedy, D. 1996. London Bus Tendering: A Welfare Balance, Transport Policy 2 (4): 243-250.

Klein, P. G. (ed.). 1993. The Fortunes of Liberalism: Essays on Austrian Economics and the Ideal of Freedom, The Collected Works of F.A. Hayek, Volume IV, London: Routledge.

Mackie, P., J. Preston, and C. A. Nash. 1995. Bus Deregulation: Ten Years On, Transport Reviews, 15(3): 229-251

Mackie, P., and J. Preston. 1996. The Local Bus Market: A Case Study of Regulatory Change, Aldershot: Avebury.

Nash, C. A. 1988. Integration of Public Transport: An Economic Assessment, in Dodgson, J.S., and N. Topham (eds.), Bus Deregulation and Privatization: An International Perspective, Aldershot: Avebury: 97-118. 
Porter, M. E., and C. Van Der Linde. 1995. Toward a New Conception of Environment-

Competitiveness Relationship, Journal of Economic Perspectives 9 (4): 97-118. Salomon, I., P. Bovy, and J. P. Orfeuil (eds). 1993. A Billion Trips a Day: Tradition and

Transition in European Travel Patterns, Dordrecht: Kluwer Academic Publishers. Toleman, R. 1995. Refocussing the Role of Government in Transport: The New Zealand

Experience, paper presented to 7th World Conference on Transport Research, July 16-21, Sydney.

Tyson, W. J. 1995 Bus Deregulation-The Planning Dilemma, Transport Reviews 15 (4): $307-314$.

White, P. R. 1997. What Conclusions Can be Drawn about Bus Deregulation in Britain?, Transport Reviews 17 (1): 1-16.

White, E. P. R. 1988. An Overview of Urban Minibus Operations, paper presented at Symposium on Experiences of Urban Minibus Operations in Britain, City University, London, May 12.

White, P., and R. Turner. 1991. Overall Impacts of Local Bus Deregulation in Britain, Transportation Planning and Technology 15: 203-229.

\section{Appendix A \\ Innovative Opportunities and Key Changes in Operations \\ for "Better-Practice" Operators}

Monopoly Operations

(threat of tendering only)

Specific notable changes:

(1) Enhanced cross-regional services, improved off-peak services and introduced "set-down" on request.

Overall change in kilometers:

(1) Over period $92 / 93-95 / 96$ increased by $12 \%$.

Overall change in passengers:

(1) Over period $92 / 93-95 / 96$ increased by $3 \%$.

Overall change in fare levels:

(1) Over period $92 / 93-95 / 96$, increased by $2 \%$ pa. 
Change in corporate strategy:

(1) None.

New opportunities under tendering:

(1) Nil.

Actions to reduce environmental impacts:

(1) CNG buses, Euro II engines, disability trials, all depot facilities conform to environmental standards, working with clean Air 2000 initiative in Australia.

\section{Deregulated Market}

Specific notable changes:

(1) Large buses phased out, mini/midi buses introduced with increased frequency, urban mileage increased, interurban mileage increased, greater penetration of housing estates, "hail-n-ride," rural mileage decreased.

(2) Higher frequency, minibuses and cross-town services.

(3) Concentrate marketing/product on high frequency key services.

Overall change in kilometers:

(1) Average of $10 \%$ pa increase.

(2) $8 \%$ pa increase.

(3) Increase by $5 \%$ pa.

Overall change in passengers:

(1) Average increase of $8.6 \%$ over 3 years compared to average national decline of $5 \%$.

(2) $20 \%$ pa increase.

(3) Increase by $15 \%$ over 3 years.

Overall change in fare levels:

(1) $20 \%$ increase over 6 years compared to CPI increase of $30 \%$.

(2) No real fare change.

(3) Remained static. 
Change in corporate strategy:

(1) No cross-subsidization between routes or times of day or week, no fare scales-market pricing route by route, never knowingly undersold by the competition.

(2) Emphasis on cost reduction, improved customer service and improved relationships with regulatory authority and wider community.

(3) Much more innovative and immediate in response.

New opportunities under deregulation:

(1) Market segmentation — high quality and low grade services on same route, experimented more with routes-frequencies, fares, special promotion; let the customer decide rather than a Local Authority

(2) Reduce costs and increased customer service delivery.

(3) Improve frequencies, bold expts with fares.

Actions to reduce environmental impacts:

(1) Using low sulphur diesel, choose Eurol or Euro2 specifications of vehicles, experimenting with gas vehicles.

(2) Refurbished trolley buses, extended use of trolley buses, introduced Euro I compatible diesel buses-now $30 \%$ of fleet, increased market share relatively to less environmentally friendly modes.

(3) Emission controls through Euro I and II engines.

\section{Competitive Tendering/Contracts}

Specific notable changes:

(1) Better route structures-changed $80 \%$ of what we inherited; headways no more than 30 mins, better trained drivers, introduced minibuses and major refurbishment of inherited buses.

(2) More flexibility in route design and scheduling, new buses.

Overall change in kilometers:

(1) Over 30 months, increased by $23 \%$.

(2) $12 \%$ increase. 
Overall change in passengers:

(1) Increased by $20 \%$

(2) $8 \%$ increase.

Overall change in fare levels:

(1) Increased by $5 \%$.

(2) No increase.

Change in corporate strategy:

(1) Frequencies revised significantly upwards especially off-peak and weekends; minibuses introduced into 70 new residential streets and $80 \%$ of existing routes changed.

(2) Compliance procedures in place.

New opportunities under tendering:

(1) As a new private entrant able to make all changes above, which were impossible under public monopoly.

(2) Quicker response to problems, clearer defined contract areas previously disputed with neighboring contractors.

Actions to reduce environmental impacts:

(1) Rebuilt 90 transmissions and 50 engines and introduced minibuses to give better fuel economy.

(2) None.

\section{About the Authors}

David Hensher is Professor of Management and Director of the Institute of Transport Studies: The Australian Key Centre of Teaching and Research in Transport Management in the Graduate School of Business at the University of Sydney as well as in the Department of Civil Engineering at Monash University.

Michael Beesley is Emeritus Professor of Economics at the London Business School. He was editor-in-chief of the Journal of Transport Economics and Policy in the 1980s and currently serves on four editorial boards of transport journals. 
